\title{
Simple Robust Linkages Between CDS and Equity Options
}

\author{
Peter Carr ${ }^{\mathrm{a}, \mathrm{b} *}$ Liuren $\mathrm{Wu}^{\mathrm{c} \dagger}$

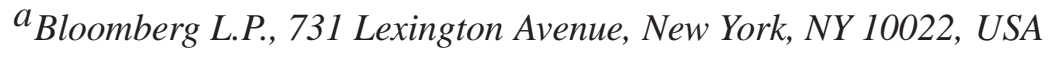 \\ ${ }^{b}$ Courant Institute, New York University, 251 Mercer Street, New York, NY 10012, USA \\ ${ }^{c}$ Baruch College, Zicklin School of Business, One Bernard Baruch Way, New York, NY 10010, USA
}

This version: January 15, 2008; First draft: September 25, 2007

\begin{abstract}
We test a theory that provides a simple and robust link between market prices of credit default swaps (CDS) and equity options. The theory links the CDS spread to the market prices of vertical spreads of American put options which are sufficiently out-of-the-money. The linkage is established under a general class of stock price dynamics for which the default event affects only the state space in which stock prices evolve. Specifically, stock prices are assumed to be bounded below by a barrier $B>0$ strictly before the default event, and to drop below an alternative barrier $A<B$ at the default time. We allow random stock price evolution after default, so long as it is bounded above by $A$. We suppose that investors can take a static position in at least two co-terminal American put options struck within the default corridor $[A, B]$. We show that a vertical spread of such options scaled by the spread between the two strikes replicates a standardized credit insurance contract that pays one dollar at default whenever the company defaults prior to the option expiry and zero otherwise. Given the above state space behavior, we show that this simple replicating strategy is robust to the details of the pre-default stock price dynamics, the post-default stock price dynamics, interest rate dynamics, and default arrival rate fluctuations. We use the value of the American put spread to infer risk-neutral default probabilities and compare them to the default probabilities estimated from CDS spreads on the same reference company. Collecting data from both markets on several reference companies with significant default probabilities, we identify a strong correlation between the default probabilities inferred from the two markets, and find that deviations between the two estimates help predict future movements in both markets.
\end{abstract}

\section{JEL Classification: C13; C51; G12; G13.}

We are grateful to Bruno Dupire, Bjorn Flesaker, Ziqiang Liu, Dilip Madan, Eric Rosenfeld, Ian Schaad, Serge Tchikanda, Arun Verma, and Yan Wang for discussions and comments. We welcome comments, including references that we have inadvertently missed.

*Tel.: +1-212-617-5056; fax: +1-917-369-5629. E-mail address: pcarr4@bloomberg.com.

${ }^{\dagger}$ Tel.: +1-646-312-3509; fax: +1-646-312-3451. E-mail address: liuren_wu@ baruch.cuny.edu. 
Keywords: Stock options; American puts; credit default swaps; default arrival rate; default probabilities. 


\section{Contents}

1 Introduction 1

2 Theory 4

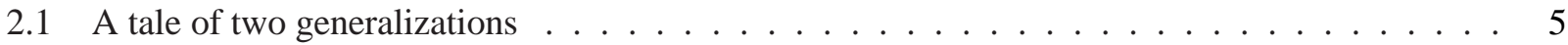

2.2 Defaultable displaced diffusion: A toy example . . . . . . . . . . . . . . . 7

2.2.1 Transition probability density function . . . . . . . . . . . . . . . 9

2.2.2 Pricing American put options $\ldots \ldots \ldots \ldots \ldots \ldots$

2.2.3 Linking American put spreads to unit recovery claims . . . . . . . . . . . . . 11

2.3 Defaultable displaced diffusion: The general specification . . . . . . . . . . . . . . . . 12

2.4 Linking unit recovery claims to CDS spreads $\ldots \ldots \ldots \ldots \ldots$

3 Data and estimation $\quad 17$

3.1 Inferring default probabilities from American put spreads $\ldots \ldots \ldots \ldots$

3.2 Inferring default probabilities from CDS spreads $\ldots \ldots \ldots \ldots$

3.3 Replicating unit recovery claims from both markets . . . . . . . . . . . . . . 20

4 Results $\quad 20$

4.1 Predicting the movements of unit recovery claims . . . . . . . . . . . . . . . 24

5 Alternative linkages $\quad 25$

6 Concluding remarks $\quad 28$

A Conditional transitional probability density function under the toy DDD model 30 


\section{Introduction}

Notional amounts in both credit and equity derivatives continue to display strong growth. In September 2007, the International Swaps and Derivatives Association, Inc. (ISDA) announced that the notional amounts outstanding of credit derivatives grew by $75 \%$ to $\$ 45.46$ trillion from $\$ 26.0$ trillion one year earlier, and the notional amounts in equity derivatives grew by $57 \%$ to $\$ 10.01$ trillion from $\$ 6.38$ trillion one year earlier. As a result of the continued strong growth in both markets, there is strong interest in understanding if and how the two markets are linked. If the payoffs are linked but the prices are not, trading opportunities arise. If payoffs and prices are both linked, the understanding of each market can be substantially improved by integrating the two markets.

For the ISDA survey, credit derivatives comprise credit default swaps referencing single names, indexes, baskets, and portfolios; equity derivatives comprise equity swaps, options, and forwards. In this paper, we focus on two segments of the credit and equity derivatives markets that show particularly strong linkages. On the credit derivatives side, we focus on credit default swaps (CDS) written on a corporate bond, which remains the largest segment by volume. On the equity derivatives side, we focus on American options written on the stock of the corresponding firm that issued the corporate bond. While there is much literature attempting to link single name CDS with single name stock options, the focus to date has been on European-style options. ${ }^{3}$ This focus is unfortunate since for single name stock options, the only transparency in pricing arises from listed options, which are all American style. We conjecture that the past focus on linkages between CDS and European options stems from the greater ease with which prices of European options can be analytically related to the underlying stock prices in standard option pricing models. In contrast, the problem of analytically relating American option prices to the underlying stock price is notoriously difficult.

In this paper, we show that the spread between two American put options with a particular strike range can be used to directly synthesize a standardized credit insurance contract that pays one dollar at default whenever the company defaults prior to the option expiry and zero otherwise. This direct linkage between American put options and credit contracts holds true under a wide class of stock price dynamics. The key assumption for this class of price dynamics is that random stock prices are bounded below by a barrier $B>0$ before default and drop below an alternative barrier $A \in[0, B)$ at default. After the default time and before expiry, the stock price dynamics are bounded above by $A$. As long as these conditions are satisfied, the simple linkage

\footnotetext{
${ }^{3}$ Examples include Bakshi, Madan, and Zhang (2006), Carr and Wu (2005), Collin-Dufresne, Goldstein, and Martin (2001), Cremers, Driessen, Maenhout, and Weinbaum (2004), and Hull, Nelken, and White (2004).
} 
holds robustly, irrespective of the details of the stock price dynamics before and after default, the interest rate dynamics, and default arrival rate fluctuations.

Classic structural models of default, e.g., Merton (1974), have the property that prior to default, the firm value is random and bounded below by the default barrier. In such models, stock prices vanish at default and remain zero afterwards. In a recent paper, Carey and Gordy (2007) show that private debtholders play a key role in setting the endogenous asset value threshold below which corporations declare bankruptcy. In particular, the private debtholders often find it optimal to force the bankruptcy well before equity values vanish. Our specification of the stock price dynamics is in line with such evidence.

Suppose that investors can take static positions in at least two American put options of the same maturity $T$ and whose strikes $\left(K_{1}>K_{2}\right)$ lie within the default corridor $(A, B)$. Given that the stock price is bounded below by $B>0$ before default, and is bounded above by $A<B$ at and after default, then a simple vertical spread of the two American put options scaled by the strike distance, $U_{t}(T) \equiv\left(P_{t}\left(K_{1}, T\right)-P_{t}\left(K_{2}, T\right)\right) /\left(K_{1}-K_{2}\right)$, replicates a standardized credit insurance contract that pays off one dollar whenever default occurs up to the option expiry and zero otherwise. Without default, the stock price stays above $K_{1}$, and hence both put options will not be exercised as they always have zero intrinsic value. If default occurs prior to the option expiry, then the stock price falls below $K_{2}$ and stays below it afterwards. We will show that both options are optimally exercised at the default time as a result, so that the scaled spread nets a payoff of one dollar at this time. If we further assume that the stock price falls to zero at the default time $(A=0)$, then we can set $K_{2}=0$ and use a single American put option to construct this credit insurance contract, $U_{t}(T)=P_{t}\left(K_{1}, T\right) / K_{1}$.

We refer to this standardized credit contract as a unit recovery claim. ${ }^{4}$ This fundamental claim is simply a fixed-life Arrow Debreu security paying off one dollar when the (default) event occurs, and zero otherwise. Since American put options trade simultaneously at several discrete maturities, it is possible to interpolate and extrapolate in the maturity dimension to obtain a term structure of synthetic unit recovery claims. By assuming deterministic interest rates, we can readily compute the risk-neutral default probabilities from this term structure.

To link the American stock options to the credit default swap (CDS) spreads on the same reference company, we assume that the recovery rate on the corporate bond underlying the CDS contract is known. Then, the value of the protection leg of the CDS contract becomes proportional to the value of the unit recovery claim, which we can replicate using two American put options. Once the value of the protection leg becomes

\footnotetext{
${ }^{4}$ The Chicago Board of Options Exchange (CBOE) has recently launched unit recovery claims under the name Credit Event Binary Option (CEBO).
} 
a known function of its maturity, one can uniquely determine the CDS spread curve by further assuming deterministic interest rates. Alternatively, one can take the CDS spread curve as given, strip it for the value of the protection leg, and then back out the implied recovery rate on the bond using the observable American put spread.

To empirically test the strength of the linkage between the two markets, we choose eight reference companies from the components of the North American High Yield CDS Index (CDX). The Index is composed of 100 non-investment grade entities, distributed amoung three sub-indices: B, BB, and HB. The composition of the high yield index and each sub-index is determined by a consortium of 16 member banks. The indices roll every six months in March and September of each year. We take the 100 components from the index rolled out in September of 2007 and take eight companies that we have viable quotes on both CDS and American put options. The CDS quotes are obtained from Bloomberg. The American options quotes are obtained from OptionMetrics. We take the sample period from January 2005 to June 2007. From the options data set, at each date we synthesize the value of the unit recovery claim at all observable maturities, compute the risk-neutral default probabilities while assuming deterministic interest rates, and interpolate to obtain the risk-neutral default probability at one-year fixed time-to-maturity. From the CDS data, we use the one-year CDS spread to also compute the one-year risk-neutral default probabilities assuming fixed bond recovery rates and deterministic interest rates. Then, we compare the two time series of default probabilities for each reference company. First, we find that the strike choices in defining the American put spread can induce some biases in the default probability estimates. Nevertheless, the probabilities obtained from the American put spreads are on average close to those computed from the CDS spread. Furthermore, for each company, the two time series of default probabilities show high cross-correlations, especially when the default probability is significant. The crosscorrelation estimates are over $80 \%$ when the default probabilities are over $2 \%$. Furthermore, we find that deviations between the two default probability estimates can help predict future movements in both markets.

In linking credit insurance to American equity options, we make assumptions on the stock price dynamics that lie between structural and reduced-form models. As in structural models, we assume that default occurs the first time that the stock price crosses a lower barrier, which does not need to be constant but nevertheless needs to have a fixed lower bound. As in reduced form models, we assume that the waiting time to default is completely unanticipated. The main innovation in our specification is that the default barrier is expanded into a default corridor $(A, B)$. The stock price is assumed to evolve randomly above the default corridor prior to the default time, to drop below the default corridor at default, and to evolve deterministically afterwards. It is these three behavioral modes that generate the tight linkage between the American options and the CDS 
markets.

For comparison, we also implement a simple version of Merton (1974)'s structural model to compute the one-year default probabilities by using information in the capital structure and the return volatility. In the implementation, we use stock price to proxy the per share equity value, net debt per share to proxy the per share face value of debt, and one stock option implied volatility to proxy for return volatility. Based on these inputs, we compute the firm value and firm volatility, with which we compute the risk-neutral probability that the stock price will stay above the face value of the debt at the one-year horizon. We use one minus this probability as a measure for the one-year risk-neutral default probability from this model. We find that the default probabilities estimated from the structural model are significantly lower than those obtained from the American puts or those from the CDS spreads. Nevertheless, the estimates can show high cross-correlations with the default probabilities inferred from the CDS spread, especially if we use the implied volatility of out-of-the-money American put options as the stock return volatility input. This exercise shows that the real information in the stock market on credit risk is in out-of-the-money put options, as we have shown in our simple robust linkage.

The rest of the paper is structured as follows. The next section lays down the theoretical framework, under which we build the tight linkage between the American stock options market and the CDS market. In this section, we first review two simple generalizations of the standard option pricing model proposed by Black and Scholes (1973) and by Merton (1973). Then we combine the two generalizations to set up a toy example of our modeling framework under which we can price American options analytically and link the American put spreads to unit recovery claims. Finally, we specify the general class of models, under which

the simple linkage between American put spreads and CDS spreads remain robust. Section 3 describes the data that we use for our empirical work and the procedure that we follow to estimate one-year risk-neutral default probabilities from the two markets. Section 4 compares the two time series of default probabilities for each company. Section 5 estimates the risk-neutral default probability from a simple structural model and compares the estimates to those obtained from the American puts and the CDS market. Section 6 offers concluding remarks and directions for future research.

\section{Theory}

Black and Scholes (1973) and Merton (1973) propose an option pricing model, henceforth the BMS 
model, that has since revolutionized the derivative industry. The main assumptions underlying the BMS model are that investors can trade continuously over time, that sample paths of the underlying stock price are continuous, and that the stock's return volatility is constant. As the model also assumes no arbitrage and constant proportional carrying costs for the stock, the risk-neutral stock price process is simply geometric Brownian motion. When this diffusion process is started from a positive level, it can never hit zero.

In what follows, we first review two generalizations of the BMS model proposed by Merton (1976) and Rubinstein (1983), respectively. Inspired by these generalization, we propose our modeling framework, under which we build the linkages between credit insurance and American equity options.

\subsection{A tale of two generalizations}

For companies with positive default probabilities, the stock price going to zero is a definite possibility. After a company defaults, its stock price is likely to be low and it is common to assume that the stock price is in fact zero after bankruptcy. Recognizing that the underlying stock price dynamics in the BMS model are not consistent with this default-related behavior, Merton (1976) generalizes the dynamics by allowing the possibility for the stock price to jump to zero. We refer to this model as the Merton-Jump-to-Default model or simply MJD. As the stock of a company is a limited liability asset, the MJD model realistically assumes that the stock price remains at zero after the jump time.

Assuming that the risk-neutral arrival rate of such a jump is constant, we can still replicate the payoff of a European call option in the MJD model by dynamically trading just the stock and a corporate bond whose value also vanishes upon default. The addition of the bankruptcy state does not destroy our ability to replicate the payoff of the call option as long as we can use a corporate bond instead of a default-free bond as a hedge instrument. The reason is that the value of the target call option and the value of the stock-bond hedging portfolio both vanish upon default.

Since the payoff of the call option can be replicated, its price is uniquely determined by no arbitrage. Merton (1976) shows that the only effect on the BMS call pricing formula of using the MJD model is to cause the stock growth rate and call discount rate to both increase by the risk-neutral default arrival rate. The reason for these changes becomes clear once we recognize that the option pricing formula relates the call price at any future time to the contemporaneous stock price, conditioning on no prior default. The requirement that the unconditional risk-neutral expected return on the stock and the call both be the riskfree rate forces the conditional growth rate in each asset to be higher, as the values for both assets drop to zero upon default. 
Since each asset drops by $100 \%$ of its value, the conditional growth rate of each asset must exceed the riskless rate by the default arrival rate.

Once the linkage between the value of a European call and its underlying stock has been established, the link between the value of a European put and its underlying stock is established by put-call parity. Merton (1976) does not address the pricing of American options, but it is straightforward to analyze the impact of a jump to default on the optimal exercise strategy. When the underlying stock pays sufficiently small dividends, it is still the case that American calls are not exercised early (see Merton (1973)). So long as the riskfree rate is positive and dividends are sufficiently small, it is also still the case that American puts always have positive probability of early exercise. As in the case with no jump to default, the optimal exercise strategy is to exercise the American put once the stock price enters a stopping region. As this region contains the origin, the American put will be exercised early if there is a jump to default. It will also be exercised early if the stock price diffuses down to an exercise boundary. The analytic determination of this exercise boundary is a difficult problem and is the main hindrance in analytically valuing American puts in either the MJD or BMS model.

The MJD model extends the BMS model to include bankruptcy while preserving tractability. In evaluating the validity of any extension of the BMS option pricing model, it is common to use the notion of option implied volatility. The implied volatility of an option is defined as the constant volatility input that one must supply to the BMS option pricing model in order to have the BMS model value agree with a given option price. The given option price can be produced by either the model or the market and hence implied volatilities can likewise be produced by either the model or the market. The model implied volatility of the BMS model is invariant to strike price. In contrast, the model implied volatility of the MJD model is always decreasing in the strike price, generating what is commonly referred to as an implied volatility skew.

Motivated by the possibility of producing an analytically tractable European option pricing model for which implied volatilities can decrease or increase in strike, Rubinstein (1983) introduces the displaced diffusion option pricing model, henceforth the RDD model. In this model, Rubinstein relaxes the requirement in the BMS model that the state space of the underlying stock price diffusion be the whole positive real line. Specially, let $S_{0}>0$ denote the initial stock price, Rubinstein introduces a new parameter $B \in\left(-\infty, S_{0}\right)$. Assuming a constant interest rate $r$, an initial investment of $B$ in the riskfree asset would grow to $B e^{r t}$ by time $t$. Rubinstein suggests that the risk-neutral process for the underlying stock price be constructed by summing $B e^{r t}$ with a geometric Brownian motion. As a result, the state space of the underlying stock price process at 
any time $t$ is $\left(B e^{r t}, \infty\right)$ rather than $(0, \infty)$.

As with the MJD model, Rubinstein's displaced diffusion is an extension of the BMS model while maintaining the analytical tractability. However, the RDD model has some properties that are not shared by either the BMS or MJD model. In particular, if $B$ is positive, levels in $\left(0, B e^{r t}\right)$ cannot be reached by the stock price. It can be shown that the implied volatilities produced by this positively displaced diffusion are an increasing function of strike $K \in\left(B e^{r t}, \infty\right)$. If $B$ is negative, levels in $\left(B e^{r t}, 0\right)$ can be reached by the stock price, and the implied volatilities produced by the negatively displaced diffusion are a decreasing function of strike $K \in\left(B e^{r t}, \infty\right)$. The RDD model collapses to the standard BMS model when the displacement $B$ is zero.

It is interesting to compare the two generalizations of the BMS, the MJD and the RDD model. Merton's generalization introduces a scale factor $e^{\lambda t}$ on the allowed sample paths, while Rubinstein's generalization introduces a shift $B e^{r t}$. Under MJD model, the underlying stock price has a state space of $[0, \infty)$ and the model implied volatility can only stay constant or decline in strike price. Under RDD, the underlying stock price has a state space at time $t$ of $\left(B e^{r t}, \infty\right)$ and the model implied volatility either increases with the strike when $B>0$ or decreases with the strike when $B<0$. Neither model can produce a U-shaped relation between implied volatility and strike price, a shape that is the most commonly observed in the market and is often referred to as the implied volatility smile. To generate smile-consistent dynamics, we propose to combine the two generalizations to both scale and shift the sample paths.

\subsection{Defaultable displaced diffusion: A toy example}

Before we lay out the general model specification, we start with a toy example to illustrate the ideas behind the linkage between credit spreads and the value spread of two American puts. Our specification allows for both default as in the MJD model and diffusion displacement as in the RDD model. Taken together, we label the class of models that we propose as defaultable displaced diffusion, or the DDD model.

As in earlier generation models, we assume frictionless markets, no arbitrage, and the existence of a riskfree asset with strictly positive paths of bounded variation. As a result, there exists a risk-neutral measure $\mathbb{Q}$ under which all tradeable securities have an expected return equal to the riskfree rate. We use $T$ to denote the common expiry date of the options and credit contracts. We assume that the underlying stock pays no dividends over $[0, T]$ and we let $r \geq 0$ be the assumed constant riskfree rate over this horizon.

To intuitively describe the risk-neutral stock price dynamics in the toy DDD model, we start with the stock 
price $S$ following Rubinstein (1983) displaced diffusion over the fixed time horizon $t \in[0, T]$. The stock price process is assumed to be positively displaced, with $B \in\left(0, S_{0}\right]$. Then, we depart from Rubinstein's model by adding the possibility of a down jump in the stock price. If the first jump in the stock price happens to occur at time $T$, we assume that the stock price jumps to some constant $R \in[0, B)$. More generally, if the stock price jumps at some time $t \in[0, T]$, we assume that it jumps to the deterministic recovery level $R(t) \equiv R e^{-r(T-t)}$. After the jump time $\tau$, the stock price grows deterministically at the riskfree rate $r$, i.e. $S_{t}=R(t)$ for $t \geq \tau$. The risk-neutral arrival rate of the jump in the stock price is assumed to be constant at $\lambda \geq 0$.

To formally model the risk-neutral stock price dynamics in the toy DDD model, we introduce a standard Brownian motion $W$ and a standard Poisson process $N$ with intensity $\lambda$. We let $G$ be a geometric Brownian motion defined by

$$
G_{t}=e^{\sigma W_{t}-\sigma^{2} t / 2}
$$

with $G_{0}=1$ and where $\sigma$ is a real constant. The random process $G$ is a martingale started at one. We let $J$ be another martingale started at one defined by

$$
J_{t}=1\left(N_{t}=0\right) e^{\lambda t}
$$

This process drifts up at a constant growth rate of $\lambda$ and jumps to zero and stays there at a random and exponentially distributed time. It is easy to see that $G$ and $J$ are both martingales since equations (1) and (2) imply that they respectively solve the following stochastic differential equations,

$$
d G_{t}=\sigma G_{t} d W_{t}, \quad d J_{t}=-J_{t-}\left(d N_{t}-\lambda d t\right)
$$

where the subscript $t$ - indicates that the pre-jump level is used at time $t$. As a result, $J$ is a right continuous left limits (RCLL) process.

We construct the stock price process $S$ by combining the two random processes $G$ and $J$ as

$$
S_{t-}=e^{r t}\left\{R(0)+J_{t-}\left[B-R(0)+\left(S_{0}-B\right) G_{t}\right]\right\} .
$$

To understand this RCLL stock price process, we can rewrite the stock price process as the sum of three components,

$$
S_{t-}=R(0) e^{r t}+[B-R(0)] e^{r t} J_{t-}+\left(S_{0}-B\right) e^{r t} J_{t-} G_{t} .
$$


Each component has the form of a constant, multiplied by $e^{r t}$, and then a martingale. Therefore, each component can be interpreted as the time- $t$ value resulting from investing the constant in an asset whose initial price is one. In this sense, we are attributing the equity value of a firm to returns from three types of investments. The first type is a riskless cash reserve defined by the deterministic and non-negative process $R(t)=R(0) e^{r t}$. The second type is a defaultable risky cash reserve defined by the stochastic and non-negative process $[B-R(0)] e^{r t} J_{t-}$, with the martingale $J_{t-}$ capturing the default risk. The third type of investment is a defaultable and market risky asset defined by the stochastic and non-negative process $\left(S_{0}-B\right) e^{r t} J_{t-} G_{t}$, with the martingale $G_{t}$ capturing the market, diffusion-type variation. ${ }^{5}$ Under the risk-neutral measure $\mathbb{Q}$, all three investments generate a risk-neutral expected return of $r$.

From equation (4), we can derive the stochastic differential equation for the stock price dynamics,

$$
d S_{t}=r S_{t-} d t-\left(S_{t-}-R(t)\right)\left(d N_{t}-\lambda d t\right)+\left\{S_{t-}-\left[R(t)+(B-R(0)) J_{t-} e^{r t}\right]\right\} \sigma d W_{t},
$$

where the exposures to the martingale increments $d N_{t}-\lambda d t$ and $d W_{t}$ are both affine in the stock price $S_{t-}$. Since no jumps occur before default, the pre-default stock price dynamics simplify to,

$$
d S_{t}=\left[r S_{t-}+\lambda\left(S_{t-}-R(t)\right)\right] d t+\left\{S_{t-}-\left[R(t)+e^{\lambda t}\left[B e^{r t}-R(t)\right]\right\} \sigma d W_{t}, \quad t \in[0, \tau),\right.
$$

where both drift and the diffusion coefficient of the stock price dynamics are affine in the stock price.

If we set $\lambda=0$ in the toy DDD model, the model degenerates to the positively displaced diffusion of Rubinstein (1983), for which implied volatility increases with strike. Conversely, if we set $B=0$, the model degenerates to Merton (1976)'s MJD model, for which implied volatility decreases with strike. When $\lambda$ and $B$ are both positive, the implied volatility smiles when graphed against the strike price. This model behavior is broadly consistent with the behavior of implied volatilities obtained from market prices of listed American stock options.

\subsubsection{Transition probability density function}

In this toy model, the transition probability density function (TPDF) of the stock price can be derived in closed form. Let $\underline{K}(t) \equiv R(0) e^{r t}+[B-R(0)] e^{(r+\lambda) t}$. For $K>\underline{K}(T)$ and $S>\underline{K}(t)$, the TPDF conditional on

\footnotetext{
${ }^{5}$ The stock price dynamics can also have jumps. For simplicity, we exclude this possibility in our toy example, but we incorporate jumps in the general DDD specification.
} 
surviving to $T$ is $^{6}$

$$
\mathbb{Q}\left\{S_{T} \in d K \mid S_{t}=S, N_{T}=0\right\}=\frac{\left.\exp \left\{-\left[\ln h(K, S)+\sigma^{2}(T-t) / 2\right] / \sigma \sqrt{T-t}\right]^{2} / 2\right\}}{\sqrt{2 \pi \sigma^{2}(T-t)}} \frac{1}{K-R-[B-R(0)] e^{(r+\lambda) T}} .
$$

The risk-neutral probability of defaulting over $[t, T]$ is simply $1-e^{-\lambda(T-t)}$ and this is also the risk-neutral probability that $S_{T}=R$, given that $S_{t}=S>\underline{K}(t)$. One can easily use these results to develop closed form formulas for European options. As no listed single name stock options are European, we leave this as an exercise to the interested reader.

\subsubsection{Pricing American put options}

Prior to default, $J_{t}=e^{\lambda t}$ and $G_{t}>0$, so (5) implies that the stock price $S_{t}$ exceeds $B(t) \equiv R(0) e^{r t}+[B-$ $R(0)] e^{(r+\lambda) t}$. At the default time $\tau, J_{\tau}=0$, and the stock price jumps down to the riskless cash reserve level $R(\tau) \equiv R e^{-r(T-\tau)}$. After the default, the stock price $S_{t}=R e^{-r(T-t)}$. Since $\underline{K}(t) \geq B$ and $R(t) \leq R$, we observe that the stock price process is random and at least $B$ in the pre-default period $t \in[0, \tau \wedge T]$, and becomes deterministic and at most $R$ in the post-default period, $t \in[\tau, T]$. These special properties allow us to derive a closed-form solution for the value of of American puts struck below $B$.

Let $K$ denote the strike price of an American put maturing at $T$. If $K \in[0, R(0)]$, the put is worthless since it cannot finish in the money in the toy DDD model. If $K \in(R(0), R]$, at any time $t$ before default, the stock price is above $B$ and hence the strike price $K$. To define the continuation and exercise regions, let $t^{*}$ solve $R e^{-r\left(T-t^{*}\right)}=K$. If default occurs at some time $\tau$ in $\left(0, t^{*}\right)$, then $S_{\tau}<K$ and it is optimal to exercise at $\tau$. If default occurs in $\left[t^{*}, T\right]$, then $S_{\tau} \geq K$ and it is better to hold on to the American put and let it expire worthless. Therefore, for such puts, the continuation region is the union of all stock prices above $B(t)$ and the curve $R(t), t \in\left[t^{*}, T\right]$, while the exercise region is just the curve $R(t), t \in\left[0, t^{*}\right]$. The payoff from holding such an American put is $K-R(\tau)$ at time $\tau$ if $\tau \leq t^{*}$ and zero otherwise. Let $P_{0}(K, T)$ denote the time-0 value of an American put. By risk-neutral valuation, we have,

$$
\begin{aligned}
P_{0}(K, T) & =\mathbb{E}^{\mathbb{Q}}\left\{e^{-r \tau}[K-R(\tau)] 1\left(\tau \leq t^{*}\right)\right\}=\int_{0}^{t^{*}} \lambda e^{-\lambda t} e^{-r t}\left[K-R e^{-r(T-t)}\right] d t \\
& =\lambda\left[K \frac{1-e^{-(r+\lambda) t^{*}}}{r+\lambda}-\operatorname{Re}^{-r T} \frac{1-e^{-\lambda t^{*}}}{\lambda}\right] .
\end{aligned}
$$

\footnotetext{
${ }^{6}$ Refer to Appendix A for a proof.
} 
If $K \in(R, B]$, then $t^{*}>T$ and hence the continuation region is all stock prices above $B(t)$, while the exercise region is just the curve $R(t), t \in[0, T]$. The put value is obtained by simply replacing $t^{*}$ with $T$ in equation (9),

$$
P_{0}(K, T)=\lambda\left[K \frac{1-e^{-(r+\lambda) T}}{r+\lambda}-R^{-r T} \frac{1-e^{-\lambda T}}{\lambda}\right]
$$

For American puts options struck above $B$, finite difference methods can be used to numerically approximate the American put value $P(S, t)$ and the free boundary $S^{*}(t), t \in[0, T]$. For $S>S^{*}(t), t \in[0, T]$, the American put value $P(S, t)$ solves the partial differential equation,

$$
\left[G+\frac{\partial}{\partial t}\right] P(S, t)=r P(S, t)
$$

where

$$
\mathcal{G} \equiv \frac{\sigma^{2}}{2}\left\{S-\left[R(t)+e^{\lambda t}\left[B e^{r t}-R(t)\right]\right\}^{2} \frac{\partial^{2}}{\partial S^{2}}+\{r S+\lambda[S-R(t)]\} \frac{\partial}{\partial S}\right.
$$

subject to the terminal condition

$$
P(S, T)=(K-S)^{+}, \quad S>S^{*}(T),
$$

and the boundary conditions:

$$
\lim _{S \downarrow S^{*}(t)} P(S, t)=K-S^{*}(t) \text { and } \lim _{S \downarrow S^{*}(t)} \frac{\partial}{\partial S} P(S, t)=-1, \quad t \in[0, T] .
$$

For $S \leq S^{*}(t), t \in[0, T]$, the American put value $P(S, t)=K-S$.

\subsubsection{Linking American put spreads to unit recovery claims}

Now suppose that we observe the market prices of at least two out-of-the-money American put options of maturity $T$. Let $K_{1}$ and $K_{2}$ denote the associated strike prices and we require that $R \leq K_{1}<K_{2} \leq B$. Since $S_{t} \geq B$ prior to the default time, we know that neither put will be exercised if the firm survives to $T$. In contrast, if the firm defaults at some time $\tau$ before $T$, since $S_{\tau} \leq K_{1}$ and grows deterministically thereafter, both puts will be exercised at $\tau$. Let $\triangle K \equiv K_{2}-K_{1}$ and $\triangle P_{0}(T) \equiv P_{0}\left(K_{2}, T\right)-P_{0}\left(K_{1}, T\right)$, where $P_{0}\left(K_{1}, T\right)$ and $P_{0}\left(K_{2}, T\right)$ are the two observable put option prices. Suppose that an investor buys $\frac{1}{\Delta K}$ units of the $K_{2}$ put and writes an equal number of the $K_{1}$ put, the cost of this position is $\frac{\Delta P_{0}(T)}{\triangle K}$, which we refer to as the American 
put spread.

If no default occurs prior to expiry $(\tau>T)$, the American put spread expires worthless. If $\tau \leq T$, the American put spread pays out one dollar so long as both parties behave optimally. Furthermore, so long as the American put prices are consistent with optimal behavior as is usually assumed, these prices can be used to value credit derivatives.

To illustrate this point, consider a unit recovery claim, which pays one dollar at $\tau$ if $\tau \leq T$ and zero otherwise. Let $U_{0}(T)$ denote the arbitrage-free spot value of this claim. In the toy DDD model, this value is

$$
U_{0}(T)=\int_{0}^{T} \lambda e^{-(r+\lambda) t} d t=\lambda \frac{1-e^{-(r+\lambda) T}}{r+\lambda}
$$

Unfortunately, if the only assets with observable prices are the riskfree asset and the stock, one cannot infer the required input $\lambda$. Fortunately, if the observable prices are those of two American puts $P_{0}\left(K_{2}, T\right)$ and $P_{0}\left(K_{1}, T\right)$, hten no arbitrage dictates that the value of this unit recovery claim is equal to the value of the American put spread:

$$
U_{0}(T)=\frac{\triangle P_{0}(T)}{\triangle K}
$$

As we will show, this simple equation holds under much more general conditions and can be regarded as the fundamental result of this paper.

Furthermore, under the toy DDD model, we can equate the two right hand sides of equations (15) and (16) to numerically determine $\lambda$ from the observation of the riskfree rate $r$ and the American put spread $\frac{\triangle P_{0}(T)}{\triangle K}$. As a result, we can compute the risk-neutral default probability over a fixed horizon $[0, T]$ as $1-e^{-\lambda T}$.

\subsection{Defaultable displaced diffusion: The general specification}

The toy DDD model places strong restrictions on the stock price dynamics to show clearly the tight linkages between American put spreads and default contingent claims. In this subsection, we show that the fundamental linkage as shown in equation (16) remains valid, even if we relax the assumptions of the toy DDD model substantially. In particular, we can generalize the toy model along four major dimensions.

- Random Interest Rates: In the toy DDD model, the riskfree interest rate is fixed as a constant. In the general specification, we allow the spot interest rate $r$ to be a nonnegative stochastic process. As a result, there exists a money market account whose initial balance is one and whose balance at time 
$t \in[0, T]$ is given by $\beta_{t} \equiv e^{\int_{0}^{t} r_{s} d s}$. No arbitrage dictates that there exists a probability measure $\mathbb{Q}$ under which the gains process from any admissible trading strategy deflated by $\beta$ is a martingale.

- Random Stock Recovery: In the toy DDD model, the stock price evolves randomly above $B$ prior to default, while the recovery value $R(t)$ evolves deterministically below a level $R<B$ afterwards. In the general DDD class of stochastic processes, the stock price can be random at the default time and afterwards, but it must evolve below a barrier $A<B$ in any post-default period $t \in[\tau, T]$. To define these post-default dynamics, let $(A, B)$ be the default corridor with $A \geq 0$ and $B<S_{0}$. Let $R_{t}$ be the spot price of an asset with support $[0, A]$ over $[0, T]$. We may write its stochastic differential equation as:

$$
d R_{t}=r_{t} R_{t} d t+d M_{t}^{R}, t \in[0, T]
$$

where $M^{R}$ is a $\mathbb{Q}$ martingale. We simply set $S_{t}=R_{t}$ in any post-default period $t \in[\tau, T]$.

- Stochastic Default Arrival: In the toy DDD model, the risk-neutral default arrival rate is constant. In the generalization, the risk-neutral default arrival rate $\lambda$ is a nonnegative stochastic process. We define $J_{t}=1\left(N_{t}=0\right) e^{\int_{0}^{t} \lambda_{s} d s}$ where $N$ is now a counting process. We note that $J$ is a stochastic exponential since it solves:

$$
d J_{t}=-J_{t-}\left[d N_{t}-\lambda_{t} d t\right] .
$$

Furthermore since $N_{t}-\int_{0}^{t} \lambda_{s} d s$ is a martingale, so is $J$. We require that the martingale $J$ be independent of the process $R$.

- Stochastic Volatility and Jumps: In the toy DDD model, the market risk driver is a Geometric Brownian Motion, denoted as $G_{t}$. In the general specification, we allow the market risk driver $G$ to be the stochastic exponential of a martingale $M^{G}$, i.e., $G_{t}=\mathcal{E}\left(M^{G}\right)$. As a result, $G$ still starts at one and is still a martingale since

$$
d G_{t}=G_{t-} d M_{t}^{G}
$$

The process $G$ is now allowed to jump, but we assume that jumps in $M^{G}$ are bounded below by -1, so that $G$ is nonnegative. We furthermore require that the martingale $G$ be independent of the martingale $J$. In contrast, $G$ can depend on $r, \lambda$, and $R$.

To contend with this four dimensional generalization, we construct the stock price process as:

$$
S_{t}=\left(1-J_{t}\right) R_{t}+e^{\int_{0}^{t} r_{s} d s} J_{t}\left[B+\left(S_{0}-B\right) G_{t}\right]
$$


where $R_{0-} \equiv R_{0}$. We can again express $S$ as the sum of three stochastic processes,

$$
S_{t}=R_{t}-J_{t} R_{t}+e^{\int_{0}^{t} r_{s} d s} J_{t}\left[B+\left(S_{0}-B\right) G_{t}\right], \quad t \in[0, T) .
$$

For $t \in[0, \tau \wedge T]$, the first term $R_{t}$ is clearly an asset price process, as indicated in equation (17). Since the martingale $J$ is a stochastic exponential and is orthogonal to $R$, the product $J R$ is also an asset price process for $t \in[0, \tau \wedge T]$. Since the martingales $J$ and $G$ are orthogonal, the process $J_{t}\left[B+\left(S_{0}-B\right) G_{t}\right]$ is also a martingale. As a consequence, the last term in (21) is an asset price process. It follows that $S$ is also an asset price process for $t \in[0, \tau \wedge T]$. Since $N_{t}=0$ and $J_{t}=e^{\int_{0}^{t} \lambda_{s} d s}$ prior to default, the stock price dynamics over $t \in[0, \tau \wedge T)$ can also be written as,

$$
S_{t}=R_{t}\left[1-e^{\int_{0}^{t} \lambda_{s} d s}\right]+e^{\int_{0}^{t}\left(r_{s}+\lambda_{s}\right) d s}\left[B+\left(S_{0}-B\right) G_{t}\right]
$$

The stochastic differential equation that governs the stock price process prior to default becomes,

$$
d S_{t}=\left(r_{t}+\lambda_{t}\right)\left(S_{t}-R_{t}\right) d t+r_{t} R_{t} d t+\left[S_{t-}-R_{t-}-J_{t-} e^{\int_{0}^{t} r_{s} d s}\left(B-R_{t}\right)\right] d M_{t}^{G}, \quad t \in[0, \tau \wedge T] .
$$

Equation (21) treats the stock as a long position in the reserve asset with price $R_{t}$, a short position in the default risky version of this asset with price $e^{\int_{0}^{t} \lambda_{s} d s} R_{t}$ prior to default, and finally a long position in an asset worth at least $e^{\int_{0}^{t}\left(r_{s}+\lambda_{s}\right) d s} B$ prior to default. Since $e^{\int_{0}^{t} r_{s} d s} \geq 1$, the latter two positions net to at least $e^{\int_{0}^{t} \lambda_{s} d s}\left(B-R_{t}\right)$ prior to default. Since $e^{\int_{0}^{t} \lambda_{s} d s} \geq 1$, the three positions are worth at least $B$ prior to default. Thus, the stock price evolves randomly above $B$ in the pre-default period $[0, \tau \wedge T]$. If the default time $\tau$ occurs at or before $T$, the stock price jumps to $R_{\tau} \in[0, A]$, and evolves as $R$ afterwards.

Now, we assume that we observe at least two American put options with expiry date $T$ and with the two strike prices falling within the default corridor, $A \leq K_{1}<K_{2} \leq B$. Prior to default, the stock price evolves randomly above $B$, which is above the strike prices of both options. Therefore, neither option is exercised. If default occurs at or before $T$, the stock price jumps at the default time to some random recovery level $R_{\tau}$ that is below the strike prices of both options and stays below both strikes afterwards. As a result, both American puts are optimally exercised at $\tau$. These results jointly imply that

$$
U_{0}(T)=\frac{\triangle P_{0}(T)}{\triangle K}
$$

This simple equation robustly links the unit recovery claim to the American put spread. 
At the time of this writing, unit recovery claims are listed on the CBOE as Credit Event Binary Options (CEBO) with planned maturities ranging from 1 to 10.25 years. The CBOE also lists long-dated single-name put options under the name Long-term Equity AnticiPation Securities (LEAP's). LEAP maturities can be as long as 39 months from the date of the initial listing. If the prices of American put spreads and the CEBOs listed by the CBOE violate equation (24), then either the assumed dynamical restrictions in the DDD model are incorrect, or else there exists an arbitrage opportunity.

Using American put options at different maturities, we can use equation (24) to compute the values of the unit recovery claim at different maturities. If we further assume deterministic interest rates, we can strip the risk-neutral default probabilities from the term structure of unit recovery claims. Specifically, assume that the riskfree rate is a deterministic function of time $r(t), t \in[0, T]$ and let $\mathcal{S}_{0}(T)$ denote the spot price of the survival claim that pays $\$ 1$ at $T$ if $\tau>T$ and zero otherwise. Then irrespective of how default occurs, no arbitrage implies that

$$
S_{0}(T)=e^{-\int_{0}^{T} r(t) d t}-U_{0}(T)+\int_{0}^{T} r(t) e^{-\int_{t}^{T} r(s) d s} U_{0}(t) d t
$$

The equation reflects the fact that the survival claim has the same payoff as the portfolio consisting of:

- long one default-free bond paying $\$ 1$ at $T$ and costing $e^{-\int_{0}^{T} r(t) d t}$ initially.

- short one unit recovery claim maturing at $T$ and costing $U_{0}(T)$ initially.

- long $r(t) e^{-\int_{t}^{T} r(s) d s} d t$ unit recovery claims for each maturity $t \in[0, T]$, with each unit costing $U_{0}(t)$ initially.

If no default occurs before $T$, the default-free bond in the portfolio pays off the desired dollar, while all of the unit recovery claims expire worthless. If the default occurs before $T$, the value of the portfolio at the default time $\tau \in[0, T]$ becomes

$$
e^{-\int_{\tau}^{T} r(t) d t}-1+\int_{\tau}^{T} r(t) e^{-\int_{t}^{T} r(s) d s} d t=e^{-\int_{\tau}^{T} r(t) d t}-1+\int_{\tau}^{T} d e^{-\int_{t}^{T} r(s) d s}=0
$$

as desired.

Once the spot price $S_{0}(T)$ of the survival claim is known, the risk-neutral probability of defaulting over $[0, T]$ is,

$$
\mathbb{Q}\{\tau<T\}=1-e^{\int_{0}^{T} r(t) d t} S_{0}(T)=U_{0}(T) e^{\int_{0}^{T} r(t) d t}-\int_{0}^{T} r(t) e^{\int_{0}^{t} r(s) d s} U_{0}(t) d t
$$


The risk-neutral default probability and $U_{0}(T) e^{\int_{0}^{T} r(t) d t}$ are both forward prices of claims that pay one dollar if default occurs before expiry. The risk-neutral default probability is lower than $U_{0}(T) e^{\int_{0}^{T} r(t) d t}$ when interest rates are positive, because the payment time in the former claim is $T$ rather than $\tau$.

\subsection{Linking unit recovery claims to CDS spreads}

Since our ultimate objective is to compare the credit spread information from the stock options market to that from the CDS market, we go one step further in this section and use unit recovery claim values to determine the CDS spread in a fairly robust way.

For this purpose, we assume that the bond recovery rate is known at $R^{b} \in[0,1)$. Let $V_{0}^{\text {prot }}(T)$ denote the time-0 value of the protection leg of a CDS contract, which pays $1-R^{b}$ at time $\tau$ if $\tau \leq T$ and zero otherwise. As this payoff is simply $1-R^{b}$ times the payoff of a unit recovery claim, no arbitrage implies,

$$
V_{0}^{\text {prot }}(T)=\left(1-R^{b}\right) U_{0}(T)
$$

Furthermore, let $A_{0}(T)$ denote the value of a defaultable annuity, i.e., a claim that pays $\$ 1$ per year continuously until the earlier of the default time $\tau$ and its maturity date $T$. As a consequence of frictionless markets and no arbitrage, we have

$$
A_{0}(T)=\int_{0}^{T} \mathcal{S}_{0}(t) d t
$$

Assuming that the riskfree rate is a deterministic function of time $r(t), t \in[0, T]$, we can substitute (25) into (29) to relate $A_{0}(T)$ to the given term structure of unit recovery claim values,

$$
A_{0}(T)=\int_{0}^{T}\left\{e^{-\int_{0}^{t} r(s) d s}-U_{0}(t)+\int_{0}^{t} r(s) e^{-\int_{s}^{t} r(v) d v} U_{0}(s) d s\right\} d t
$$

Finally, let $k_{0}(T)$ denote the initial CDS spread of maturity $T$. We assume that spread payments are made continuously until $\tau \wedge T .^{7}$ Then, we can represent the CDS spread as

$$
k_{0}(T)=\frac{V_{0}^{\text {prot }}(T)}{A_{0}(T)} .
$$

Assuming a known bond recovery rate $R^{b}$ implies that equation (28) can be used to relate the numerator to the

\footnotetext{
'In practice, payments are quarterly, but an accrued spread payment is netted against the default payoff when default does not occur on a CDS payment date.
} 
terminal unit recovery claim value $U_{0}(T)$. Assuming deterministic interest rates implies that (30) can be used to relate the denominator to the given term structure of unit recovery claim values. Making both assumptions allows the CDS spread to be expressed in terms of unit recovery claim values,

$$
k_{0}(T)=\frac{\left(1-R^{b}\right) U_{0}(T)}{\int_{0}^{T}\left\{e^{-\int_{0}^{t} r(s) d s}-U_{0}(t)+\int_{0}^{t} r(s) e^{-\int_{s}^{t} r(v) d v} U_{0}(s) d s\right\} d t}
$$

Recall from (24) that in the DDD model, a unit recovery claim has the same value as a co-terminal American put spread:

$$
U_{0}(T)=\frac{\triangle P_{0}(T)}{\triangle K}
$$

Substituting (33) into (32), we can compute a CDS spread from two term structures of American put prices.

\section{Data and estimation}

In this section, we gauge the empirical validity of the simple theoretical linkage between American put spreads and credit default swap spreads. We collect data from both markets and perform an empirical analysis.

The CDS quotes are obtained from Bloomberg, which has provided reliable CDS quotes across a spectrum of maturities since late 2004. The American options quotes are obtained from OptionMetrics. We take the common sample period from January 2005 to June 2007. The longest option maturity is usually between one to three years. The shortest maturity available for our CDS quotes are at one year maturity. Hence, our analysis focuses on default probabilities at horizons between from one to three years.

To obtain a set of companies with reliable quotes from both markets, we apply the following criteria: (1) Bloomberg provides reliable CDS quotes for the company at one, two, and three year maturities over our sample period. (2) OptionMetrics provides non-zero bid quotes for one or more options struck more than one standard deviation below the stock price and maturing in more than 180 days. (3) The average CDS spread at one year maturity over our sample period is over 30 basis points. The first two criteria guarantee that we have the required data from both markets for our comparative analysis. The third criterion generates a set of companies with significant default probabilities. For companies with very low default probabilities, the noise due to bid offer spreads of out-of-the-money puts would swamp any default signal that these prices may possess. Based on the above criteria, we choose eight companies. Table 1 lists the tickers, the cusip numbers, and the names of the eight companies. 


\subsection{Inferring default probabilities from American put spreads}

Our model assumes the existence of a default corridor $(A, B)$ such that the pre-default stock price evolves randomly above the corridor and the stock price at default and afterwards evolves randomly below the corridor. Given knowledge of the corridor, we can choose two American put options struck within the corridor and form an American put spread that replicates a unit recovery claim. In reality, however, the location of the corridor is not known. To identify the corridor, we make the simplifying assumption that the stock price drops to zero upon default. In this case, $A=0$ and we only need to choose one American put option with strike price lower than $B$.

Under our assumptions, any put options struck lower than $B$ would serve our purpose. Since we do not observe this $B$, we start from the lowest available strike and choose the first put option with non-zero bid quote. That is, we choose the lowest available strike under which the bid quote on the American put is strictly greater than zero. Then, the value of the unit recovery claim is defined as the American put option value divided by the strike price of the option. With zero equity value recovery, we choose $K_{2}=0$ and hence $P\left(K_{2}\right)=0$. We use the mid-value of the put option to compute the value of the unit recovery claim.

As an alternative, we have also chosen the lowest non-zero bid strike as $K_{2}$ and the next strike as $K_{1}$ to define the put spread. The implied default probabilities are similar in magnitude, except that using two strikes often introduces more short-term variation in the daily estimates. From a trading perspective, using two contracts also increases transaction costs as we need to cross two bid-ask spreads instead of one. Thus, we report our results based on the single strike American put.

American put options are available at several fixed expiry dates. To construct a time series of default probabilities with a fixed time-to-maturity, at each date $t$ we first synthesize a unit recovery claim at each expiry date $T$. Then, we compute a default arrival rate $\lambda(t, T)$ from the value of each unit recovery claim based on the following equation,

$$
U(t, T)=\lambda(t, T) \frac{1-e^{-(r(t, T)+\lambda(t, T))(T-t)}}{r(t, T)+\lambda(t, T)},
$$

where $r(t, T)$ denotes time- $t$ continuously compounded spot rate with expiry date $T$, which we strip from the term structure of US dollar LIBOR and swap rates assuming piecewise constant forward rates. The LIBOR and swap rate data are obtained from Bloomberg. Equation (34) defines $\lambda(t, T)$ implicitly as a nonlinear function of the unit recovery claim value $U(t, T)$ and the corresponding interest rate $r(t, T)$. We had no 
difficulty solving this equation numerically.

Once we have solved for the default arrival rate $\lambda(t, T)$ at each expiry date $T$, we linearly interpolate the arrival rates across different time to maturities $(T-t)$ to obtain arrival rate estimates at fixed time-tomaturities of one, two, and three years. We do not extrapolate linearly; instead, when the maximum option maturity is less than the target maturity, we use the arrival rate estimated from the longest maturity options. When the shortest option maturity is greater than the target maturity, we use the arrival rate estimated from the shortest maturity options. From this approach, we construct the time series of default arrival rates at three fixed maturities, $\lambda(t, T)^{o}$ with $T-t=1,2,3$, respectively. The superscript $o$ reminds us of the fact that the arrival rates are estimated from options market information.

The relation in Equation (34) is derived under the assumption of constant interest rates and constant default arrival rates. While this appears to contradict our assumptions, it should be noted that we use this equation merely as a way of converting the unit recovery claim value to a quantity that is relatively stable across maturities. With the default arrival rates, we can compute the corresponding default probabilities as $\mathbb{Q}(t, T)^{o}=1-e^{-\lambda(t, T)^{o}(T-t)}$.

\subsection{Inferring default probabilities from CDS spreads}

We have CDS quotes at one, two, and three year maturities. To infer the default probabilities at the three horizons from the CDS quotes, we assume constant interest rates and default arrival rates as we have done for the American put spreads. Further assuming fixed bond recovery $R^{b}$ and continuous premium payment, we can directly convert the CDS spread quote $k(t, T)$ to default arrival rates as,

$$
\lambda(t, T)^{c}=k(t, T) /\left(1-R^{b}\right),
$$

where the superscript "c" on $\lambda(t, T)^{c}$ reflects the fact that the arrival rate is estimated from the CDS market. With the default arrival rates, we can compute the default probability as $\mathbb{Q}(t, T)^{c}=1-e^{-\lambda(t, T)^{c}(T-t)}$. In computing the default probabilities, we follow industry convention in fixing the bond recovery to be $40 \%$. 


\subsection{Replicating unit recovery claims from both markets}

Translating the information in both markets into default probabilities at fixed time to maturities makes it convenient for us to perform comparative time series analysis. An alternative perspective is to analyze investment returns on the synthetic unit recovery claims. The American put spread directly replicates this unit recovery claim. In particular, when we assume zero equity recovery at default, the put spread reduces to a single American put option. Tracking the return on this put option is simple.

On the other side, from the CDS market, we can infer the value of the corresponding unit recovery claim from the CDS spread quotes by combining equations (34) and (35) under assumptions of constant interest rates and default arrival rates. Carr and Flesaker (2007) show how one can theoretically replicate the unit recovery claim using CDS contracts of all prior maturities. The practical feasibility of this replication is hindered by the large transaction costs of signing many over-the-counter CDS contracts over a continuum of maturities. Thus, in this paper, we propose to use the unit recovery claim value computed from the CDS market purely as an informational source. We investigate whether information from the CDS market can help predict returns on the unit recovery claim synthesized from American put options.

\section{Results}

Table 2 compares the summary statistics of the risk-neutral default probabilities computed from the American put spreads on the left side with that computed from the CDS spreads on the right side. The last column of the table reports the cross-correlation between the two time series for each company. The three panels report the default probabilities at times to maturity of one, two, and three years.

The mean default probabilities computed from the two markets are largely in line with one another. The autocorrelation estimates are larger for CDS-implied default probabilities, potentially suggesting that the American put-implied probability contains more transient noise. For the same company, the default probabilities increase with maturities. The cross-correlation estimates between the default probabilities computed from the two markets vary across different companies. The lowest are from $\mathrm{KBH}$, with the correlation estimated at $0.207,0.352$, and 0.321 at one-, two-, and three-year maturities, respectively. The highest correlation estimates are for GM, at $0.944,0.935$, and 0.879 for the three maturities, respectively.

Figure 1 plots the cross-correlation estimates as a function of the mean default probabilities computed 
from the CDS market. Each panel represents one maturity, where the dots represent data points and the solid lines represent a local-linear smoothing fit. At all three maturities, we observe an upward sloping relation between the default probabilities and the correlation estimates. The correlations between the two markets are higher when the default probability for the underlying company is high. When default probabilities are low, the American put spreads are more likely to be contaminated by market risk components, thus reducing the cross-correlation. The noise can also be partially generated by our methodology in choosing the strikes of the American put spread. By choosing an American put option with strictly positive bid quote, the American put spread would always have positive value, regardless of how small the default probability is. Nevertheless, for a company with a low default probability, the American put value at the correct default corridor can have a zero bid value given the discrete nature of quotes.

[Fig. 1 about here.]

Figure 2 plots the mean difference between the two default probability estimates from the two markets as a function of the mean default probabilities computed from the CDS market. The difference is computed as $\mathbb{Q}^{o}-\mathbb{Q}^{c}$. Hence, a positive mean difference suggests that the American put spreads over-estimate the default probability relative to the CDS spread and vice versa. Each panel represents one maturity. The dots in each panel are data points and the solid lines are locally-linear smoothing fits. We observe that at one- and two-year maturities, the mean difference is positive when the company's mean default probability is low, but becomes negative when the company's mean default probability is high. The sign change suggests that on average, compared to the CDS spread, the American put spread tends to over-estimate the default probability when the company's default probability is low, but under-estimate this probability when the default probability is high. At the three-year maturity, the mean differences are negative for most companies. Similar to the pattern at the other two maturities, the negative bias increases with increasing default probabilities. When we perform the locally-linear smoothing fit in each panel, we obtain downward sloping lines in all three panels.

[Fig. 2 about here.]

When the default probability is low, our criterion for choosing the strike with strictly positive American put bid quote can over-estimate the default probability because part of the put value can come from the market risk. Figure 2 shows that this bias is more severe at short maturities but becomes negligible at longer maturities. On the other hand, when the default probability is high, our zero-equity-recovery assumption can 
lower the estimate for the default probability. For example, if the stock recovery $R^{s}$ is strictly greater than zero, then the American put price should be divided by $\left(K_{1}-R^{s}\right)$ instead of by $K_{1}$ to generate the value of the unit recovery claim. In this case, assuming zero stock recovery under-estimates the value of the unit recovery claim and hence also under-estimates the default probability.

Figure 3 compares the time series of the two default probability estimates for each company and at each of the three maturities. Each panel represents one company and one maturity. Within each panel, the solid line denotes the time series estimated from the American put spreads, and the dashed line represents the time series estimated from the CDS spreads. The co-movements between the two time series are obvious from the plots. Overall, we observe more transient movements in the probabilities computed from the American puts than from the CDS quotes.

[Fig. 3 about here.]

To quantify the co-movements between the two time series for each company and at each maturity, we regress the default probabilities computed from the American puts against the default probabilities computed from the CDS market,

$$
\mathbb{Q}_{t}^{o}=a+b \mathbb{Q}_{t}^{c}+e_{t}
$$

The objective of the regression is to identify their relative sensitivities. We use the less noisy $\mathbb{Q}_{t}^{c}$ series as the regressor to reduce the potential bias induced by errors-in-variables issues. We estimate the regressions using the generalized methods of moments (GMM), with the weighting matrix computed according to Newey and West (1987) with 30 lags. Table 3 reports the regression estimates, $t$-statistics, and the R-squares of the regression. If both quantities are unbiased estimates of the same risk-neutral default probability, we would expect an intercept of zero and a slope of one from this regression. Table 3 shows that the intercept estimates are mostly significantly different from zero and many of the slope estimates are significantly different from one.

One of the potential biases induced by measurement errors in the regressor is to bias the slope estimate toward zero and accordingly bias the intercept above zero. Indeed, all intercept estimates are significantly positive, and all the significant $t$-statistics on slope estimates (against the null value of one) are negative. Hence, measurement errors in the regressor can contribute to part of the results.

Given the overlapping information in the two markets, we conjecture that deviations between the two probabilities series obtained from the two markets can be used to predict future movements of the two series. 
Specifically, we use the deviations to predict future changes in the two default probability series,

$$
\Delta \mathbb{Q}_{t+\Delta t}^{o}=a^{o}+b^{o}\left(\mathbb{Q}_{t}^{o}-c \mathbb{Q}_{t}^{c}\right)+e_{t+\Delta t}^{o}, \quad \Delta \mathbb{Q}_{t+\Delta t}^{c}=a^{c}+b^{c}\left(\mathbb{Q}_{t}^{o}-c \mathbb{Q}_{t}^{c}\right)+e_{t+\Delta t}^{c},
$$

where $\Delta \mathbb{Q}_{t+\Delta t}$ denotes changes in the default probability from date $t$ to $t+\Delta t$, with $\Delta t$ being the prediction horizon. The coefficient $c$ adjusts for potential long-run scaling biases in the two series. We estimate the two equations for each company and at each maturity using an iterative procedure: Given an initial guess on $c$, we run two time series regressions to estimate the coefficients $\left(a^{o}, b^{o}, a^{c}, b^{c}\right)$. Then, we minimize the sum of the squared regression residuals to obtain the coefficient $c$. We consider prediction horizons of one, seven, and 30 days. When there are holidays or missing data, the change $\Delta \mathbb{Q}_{t+\Delta t}$ is over the horizon from $t$ to the earliest date with available data that is greater or equal to $t+\Delta t$.

Tables 4 and 6 report the estimation results for the three different prediction horizons, respectively. As a robustness check, we observe that the estimates for the co-integrating coefficients $c$ at all three prediction horizons are similar to the slope estimates from equation (36) reported in Table 3. As expected, the fraction of variance explained increases with the length of the prediction horizon. At each horizon, the R-squares for predicting the option series are larger than that for predicting the CDS series. This R-squares difference suggests that CDS quotes contain more reliable information about default probabilities than option quotes. Default information is first revealed in the CDS market.

The estimates for the slope coefficient $b^{o}$ are significantly negative for all companies at all three maturities and for all three forecasting horizons. The significantly negative estimates indicate that American put option prices tend to decline in the future if they are too high compared to the CDS spread today and likewise, they tend to increase if they are too low compared to the CDS spread today. The fraction of variance explained by the prediction ranges from $3 \%$ to $10 \%$ at a daily horizon, from $3 \%$ to $24 \%$ at a weekly horizon, and up to $40 \%$ at the monthly horizon. These results suggest that we can exploit the linkage between the two markets and use their deviations to predict future changes in prices of American put options.

The estimates for $b^{c}$ are mostly positive but insignificant. The R-squares of the prediction are mostly low. These results suggest that the deviations between the two markets have only weak predictive ability for future CDS movements. One exception is GM, for which the slope coefficient estimates are significantly positive for one- and two-year default probabilities at both daily and weekly prediction horizons. The R-squares is about $4 \%$ at daily horizon and over $11 \%$ at weekly horizon for one-year default probabilities. Hence, for some companies, the options market also helps in discovering credit risk information. The ability to predict 
three-year default probabilities is lower than for the other two maturities. This result is potentially due to the fact that three-year option quotes are not as readily available as for nearer maturities and hence most of the three-year default probability estimates arise from extrapolations.

\subsection{Predicting the movements of unit recovery claims}

Transforming the information in the options and CDS markets into default probabilities over fixed times to maturity makes it convenient for us to perform comparative time series analysis. A more practical approach is to analyze the cross-market interaction between tradable instruments, such as the unit recovery claim that pays one dollar when the company defaults prior to expiry and zero otherwise. The American put spreads directly replicate this unit recovery claim. In particular, when we assume zero equity recovery at default, the put spread reduces to a single American put option. Tracking the evolution of the American put option becomes a simple exercise. In this section, we investigate how the CDS market information helps predict the movements in the unit recovery claim synthesized from a single American put. Assuming constant interest rates, constant default arrival rates, and fixed bond recovery, we can convert the CDS spread into the unit recovery value by combining equations (34) and(35),

$$
U(t, T)^{c}=\frac{k(t, T)}{\left(1-R^{b}\right)} \frac{1-e^{-\left(r(t, T)+k(t, T) /\left(1-R^{b}\right)\right)(T-t)}}{r(t, T)+k(t, T) /\left(1-R^{b}\right)} .
$$

We analyze how this CDS-market inferred unit recovery claim value covaries with the unit recovery claim synthesized from the American put, $U(t, T)^{o}=P\left(K_{1}\right) / K_{1}$, given the assumption that $K_{2}=0$.

To generate a series of unit recovery claims from American put options, at each date, we choose the longest maturity for the American options and choose a strike $K_{1}$ for an American put option that defines the unit recovery claim. Based on the bid and ask quotes on the American put, we obtain both a bid and an ask on the unit recovery claim. From the CDS market, we first convert the CDS quotes at fixed timesto-maturity (from one to five years) to unit recovery claims using (38). Then, we linearly interpolate the unit recovery claim values across maturities to obtain the corresponding unit recovery claim that matches the option maturity. The unit recovery claim value from the CDS market is one mid value. Table 7 reports the summary statistics of the unit recovery claim mid quote obtained from the options market $\left(U^{o}\right)$ and that from the CDS market $\left(U^{c}\right)$, as well as their cross-correlations $(\rho)$ and the results from regressing $U^{o}$ and $U^{c}$. The cross-correlations and the R-squares from the level regressions are both high. The slope coefficients are all 
positive. The $t$-statistics on the slope coefficients are against the null hypothesis of one.

Figure 4 plots in solid lines the time series of the bids and asks of the unit recovery claim synthesized from American puts. The dashed line represents the regression fit from the unit recovery value from the CDS market. For AMR, EK, F, GM, and GT, the fitted value from the CDS market almost always falls within the bid-ask range of the American puts, indicating that the two markets are largely integrated. The matching for $\mathrm{CTB}$, DDS, and $\mathrm{KBH}$ are poorer.

[Fig. 4 about here.]

Similar to the predictive regressions in (37) on default probabilities, we also investigate whether the deviations between the two markets can predict future movements in the unit recovery claims obtained from the American puts,

$$
U_{t+\Delta t}^{o}=\alpha+\beta\left(U_{t}^{o}-b U_{t}^{c}\right)+e_{t+\Delta t}
$$

where we fix the cointegrating coefficient to that obtained from the level regression in Table 7. Table 8 reports the results from the predictive regression over three horizons at one, seven, and 30 days. As expected, the slope coefficients are all strongly negative. The R-squares increase with the prediction horizon. These results suggest that we can use the linkages between the two markets to predict the movements in prices of American puts.

\section{Alternative linkages}

We have proposed a simple robust linkage between CDS spreads and American put options on the stock of the same reference company. Much of the research in the literature has focused on the structural linkage between equity and debt markets following Merton (1974), who regards equity as a call option on the firm value,

$$
E_{0}=A_{0} N\left(d_{1}\right)-D e^{-r T} N\left(d_{2}\right)
$$

with

$$
d_{1}=\frac{\ln A_{0} / D+r T+\frac{1}{2} \sigma_{A}^{2} T}{\sigma_{A} \sqrt{T}}, \quad d_{2}=\frac{\ln A_{0} / D+r T-\frac{1}{2} \sigma_{A}^{2} T}{\sigma_{A} \sqrt{T}},
$$

where $E_{0}$ denotes the time- 0 equity value, $A_{0}$ denotes the firm value, $D$ the book value of debt, and $\sigma_{A}$ the volatility on the return of the firm. In particular, $N\left(d_{2}\right)$ represents the risk-neutral probability that the call 
option will finish in the money and hence the firm will not default. Therefore, $\mathbb{Q}^{f}=1-N\left(d_{2}\right)$ denotes the risk-neutral probability of default, where the superscript $f$ reflects the fact that this probability is obtained from the Merton's firm value approach.

In order to compare our approach with a widely used standard, we also perform a simple implementation of this model to compute risk-neutral default probabilities at one-, two-, and three-year maturities. In our implementation, we take the stock price as the per share equity value, and net debt per share as the face value of debt. We take an implied volatility from the stock options market as the equity return volatility $\sigma_{E}$, from which we solve for the firm value $A_{0}$ and firm volatility $\sigma_{A}$ from the following two equations using a numerical procedure,

$$
E_{0}=A_{0} N\left(d_{1}\right)-D e^{-r T} N\left(d_{2}\right), \quad \sigma_{E}=N\left(d_{1}\right) \sigma_{A} A_{0} / E_{0}
$$

where the second equation is a result of Itô's lemma.

To extract $\sigma_{E}$ from stock options prices, we start with the implied volatilities provided by OptionMetrics, which computes the implied volatility based on a binomial tree to adjust for the early exercise premium of the American options. Then, at each date and maturity, we perform local quadratic regression of the implied volatility on a standardized moneyness measure, $d=\left(\ln E_{0} / K\right) / V_{0} \sqrt{T}$, where $K$ denotes the strike of the option and $V_{0}$ denotes an average implied volatility estimate across all strikes. From the local quadratic regression, we obtain both an at-the-money implied volatility and an out-of-the-money put implied volatility at $d=-1$, so that when log price relatives are normally distributed, the log strike is one standard deviation below the expectation of the log price at expiry. We linearly interpolate the total variance at the two moneyness levels to obtain implied volatility estimates at the three fixed time-to-maturities, with which we compute the default probabilities.

The use of at-the-money implied volatility is a popular choice in empirical studies given the higher liquidity of near-the-money options and the role of at-the-money implied volatility as a proxy for the risk-neutral expected value of return volatility (Carr and $\mathrm{Wu}(2006)$ ). Our alternative choice of an out-of-the-money put implied volatility is motivated by our robust linkage result that shows that far out-of-the-money American put options can be used to synthesize a credit insurance contract that pays one dollar at default and zero otherwise. Accordingly, the implied volatility of such an option should contain credit risk information that goes beyond the Merton structural model. Nevertheless, for liquidity concerns, we do not go to the extremely far out-of-the-money strike $K_{1}$, which we have defined earlier as the lowest strike with non-zero bid option quotes. Instead we choose a one-standard deviation criterion which usually generates liquid option quotes 
while also revealing partially the credit information embedded in our earlier exercise. We empirically investigate whether incorporating such an extra layer of credit information helps improve the structural model in generating more realistic default probability predictions.

Table 9 reports the summary statistics of the default probabilities computed from this structural model using out-of-the-money stock option implied volatility in the left panel and at-the-money stock option implied volatility in the right panel. The last column under each panel reports the cross-correlation with the default probability computed from the CDS spread. When we compare the statistics in the two panels, we find that the probabilities computed using out-of-the-money put implied volatility generates higher mean default probability estimates and also higher cross-correlation estimates with the CDS-implied default probabilities. The higher cross-correlations are expected, as the out-of-the-money put implied volatility contains the information in the American put that we have used to replicate a credit insurance contract. The higher mean default probability estimates indicate that the out-of-the-money put implied volatility is on average higher than the atthe-money implied volatility, a reflection of the well-known implied volatility skew pattern, when the implied volatility is plotted against moneyness at the same maturity.

Figure 5 plots the cross-correlation estimates in the three panels on the left hand side as a function of the mean default probabilities computed from CDS spreads. The circles (data) and the solid lines (smoothed fitting) are for the default probabilities computed from out-of-the-money implied volatilities. The diamonds (data) and dashed lines (smoothed fitting) are from at-the-money implied volatilities. First, all lines are upward sloping. The cross-correlations between the default probabilities increase as the mean default probability level increases. This result is similar to the relationship we found for values of unit recovery claims synthesized from American puts and from CDS, which show higher correlation for companies with higher default probabilities. Second, the solid line almost always stays above the dashed line within each panel, suggesting that the default probability computed from out-of-the-money implied volatilities generates higher correlations with the CDS market than does the default probability computed from at-the-money implied volatilities. This result in part reveals the additional information content of out-of-the-money put options as suggested by our robust linkage results.

[Fig. 5 about here.]

In the three panels on the right hand side of Figure 5, we plot the mean differences in default probabilities between those from the Merton approach $\left(\mathbb{Q}^{f}\right)$ and that from the CDS spreads $\left(\mathbb{Q}^{c}\right)$. Again, the circles 
(data) and the solid lines (smoothed fitting) are for the default probabilities computed from out-of-the-money implied volatilities. The diamonds (data) and dashed lines (smoothed fitting) are from at-the-money implied volatilities. The two different types of implied volatilities generate different patterns for the mean biases. Using at-the-money implied volatility, the Merton approach usually generates default probability estimates lower than that computed from the CDS market. Furthermore, this negative bias increases with increasing default probabilities. In contrast, when we use the out-of-the-money implied volatility, the mean bias is negative when the default probability is low, but the bias becomes positive when the default probability is high. The literature has often found that the Merton approach generates lower default probabilities than those obtained from corporate bonds or the CDS market. ${ }^{8}$ However, our exercise shows that this negative bias no longer exists for high-default firms when we use out-of-the-money implied volatility as the input for stock return volatility. By using information in out-of-the-money put options, we incorporate the credit information not captured by the stylized Merton model.

\section{Concluding remarks}

Structural models of default have the property that prior to default, the firm value is random and bounded below by the default barrier. They also have the property that after default, stock prices have little volatility, if any. We develop a class of reduced-form models for the stock price which is consistent with these observations. Prior to default, stock prices are bounded below by a positive constant $B<S_{0}$, while after default, they are bounded above by another constant $A<B$. When the default corridor $(A, B)$ exists, risk-neutral default probabilities can be directly expressed in terms of vertical spreads of American puts struck between these levels. Furthermore, a vertical spread of American put options scaled by the difference in strikes has the same payoff as a standardized credit claim paying one dollar at default if this event occurs before the options expire, and paying zero otherwise. The replication is simple and robust to the details of the stock price dynamics before and after default. Since the two positions pay off the same amount at the same random time, the replication is also robust to the dynamics of interest rates and default arrival rates.

We use the value of the American put spread to infer the risk-neutral default probabilities and compare them to those inferred from the credit default swap (CDS) market. Collecting data from both markets on eight reference names with significant default probabilities, we identify a strong correlation between the default

\footnotetext{
${ }^{8}$ See, for example, Huang and Huang (2003), Eom, Helwege, and Huang (2004), Elton, Gruber, Agrawal, and Mann (2001), and Collin-Dufresne, Goldstein, and Helwege (2003).
} 
probabilities inferred from American put spreads and from those inferred from CDS spreads. We also find that deviations between the two estimates help predict future movements in both markets.

Our identified linkage provides fertile ground for future research. On the theoretical side, research effort should be directed towards specifying the trading strategy that should be enacted when arbitrage arises. In particular, there is an issue of how to deal with an unexercised short put in the event of default, particularly when the cost of buying this put is above its exercise value. Research effort should also be directed towards further relaxation of the assumptions. In particular, the effect of random bond recovery rates and (discrete) dividends needs to be addressed. On the empirical side, much work is needed in investigating how the put strikes should be chosen and how to deal with maturity mismatches between the two markets. 


\section{Appendix A. Conditional transitional probability density function under the toy DDD model}

Conditional on no default up to time $t$, we can rewrite the dynamics in equation (5) as,

$$
S_{t-}=R(0) e^{r t}+[B-R(0)] e^{(r+\lambda) t}+\left(S_{0}-B\right) e^{(r+\lambda) t} G_{t}, \quad t \in[0, T]
$$

Solving for $G_{t}$, we have

$$
G_{t}=\frac{S_{t-}-\left\{R(0) e^{r t}+[B-R(0)] e^{(r+\lambda) t}\right\}}{\left(S_{0}-B\right) e^{(r+\lambda) t}} .
$$

Evaluating at $t=T$ leads to

$$
G_{T}=\frac{S_{T-}-\left\{R+[B-R(0)] e^{(r+\lambda) T}\right\}}{\left(S_{0}-B\right) e^{(r+\lambda) T}} .
$$

Taking the ratio of (A3) to (A2) implies

$$
\frac{G_{T}}{G_{t}}=\frac{\left(S_{T-}-R\right) e^{-(r+\lambda)(T-t)}-[B-R(0)] e^{(r+\lambda) t}}{S_{t-}-\left\{R(0) e^{r t}+[B-R(0)] e^{(r+\lambda) t}\right\}} \equiv h\left(S_{T-}, S_{t-}\right) .
$$

Since $\frac{G_{T}}{G_{t}}=e^{\sigma\left(W_{T}-W_{t}\right)-\sigma^{2}(T-t) / 2}$, the ratio on the left hand side is lognormally distributed:

$$
\mathbb{Q}\left\{\frac{G_{T}}{G_{t}} \in d h\right\}=\frac{\left.\exp \left\{-\left[\ln h+\sigma^{2}(T-t) / 2\right] / \sigma \sqrt{T-t}\right]^{2} / 2\right\}}{\sqrt{2 \pi \sigma^{2}(T-t)} h} d h \equiv \ell(h) d h .
$$

Let $\underline{K}(t) \equiv R(0) e^{r t}+[B-R(0)] e^{(r+\lambda) t}$. For $K>\underline{K}(T)$ and $S>\underline{K}(t)$, the transition probability density conditional on surviving to $T$ is

$$
\begin{aligned}
\mathbb{Q}\left\{S_{T} \in d K \mid S_{t}=S, N_{T}=0\right\} & =\mathbb{Q}\left\{\frac{G_{T}}{G_{t}} \in d h(K, S)\right\} \frac{\partial h(K, S)}{\partial K} \\
& =\ell(h(K, S)) \frac{e^{-(r+\lambda)(T-t)}}{S-\left\{R(0) e^{r t}+[B-R(0)] e^{(r+\lambda) t}\right\}} \\
& =\frac{\left.\exp \left\{-\left[\ln h(K, S)+\sigma^{2}(T-t) / 2\right] / \sigma \sqrt{T-t}\right]^{2} / 2\right\}}{\sqrt{2 \pi \sigma^{2}(T-t)}} \frac{1}{K-R-[B-R(0)] e^{(r+\lambda) T}}(\mathrm{~A} 7)
\end{aligned}
$$




\section{References}

Bakshi, G., D. Madan, and F. Zhang, 2006, "Investigating the Role of Systematic and Firm-Specific Factors in Default Risk: Lessons From Empirically Evaluating Credit Risk Models,” Journal of Business, 79(4), 1955-1987.

Black, F., and M. Scholes, 1973, "The Pricing of Options and Corporate Liabilities," Journal of Political Economy, 81, $637-654$.

Carey, M., and M. B. Gordy, 2007, “The Bank as Grim Reaper: Debt Composition and Recoveries on Defaulted Debt," working paper, Board of Governors of the Federal Reserve System.

Carr, P., and B. Flesaker, 2007, "Robust Replication of Default Contingent Claims," working paper, Bloomberg LP.

Carr, P., and L. Wu, 2005, "Stock Options and Credit Default Swaps: A Joint Framework for Valuation and Estimation," working paper, New York University and Baruch College.

Carr, P., and L. Wu, 2006, “A Tale of Two Indices,” Journal of Derivatives, 13(3), 13-29.

Collin-Dufresne, P., R. S. Goldstein, and J. Helwege, 2003, "Is Credit Event Risk Priced? Modeling Contagion via the Updating of Beliefs," working paper, Carnegie-Mellon University, Washington University, and Ohio State University.

Collin-Dufresne, P., R. S. Goldstein, and J. S. Martin, 2001, “The Determinants of Credit Spread Changes,” Journal of Finance, 56(6), 2177-2207.

Cremers, M., J. Driessen, P. J. Maenhout, and D. Weinbaum, 2004, “Individual Stock Options and Credit Spreads," Yale ICF Working Paper 04-14, Yale School of Management.

Elton, E. J., M. J. Gruber, D. Agrawal, and C. Mann, 2001, “Explaining the Rate Spread on Corporate Bonds,” Journal of Finance, 56, 247-277.

Eom, Y. H., J. Helwege, and J. Huang, 2004, "Structural Models of Corporate Bond Pricing: An Empirical Analysis," Review of Financial Studies, 17(2), 499-544.

Huang, J.-z., and M. Huang, 2003, "How Much of the Corporate-Treasury Yield Spread is Due to Credit Risk?,” working paper, Penn State University.

Hull, J., I. Nelken, and A. White, 2004, "Mertons Model, Credit Risk and Volatility Skews," Journal of Credit Risk, $1(1), 8-23$.

Merton, R. C., 1973, "Theory of Rational Option Pricing," Bell Journal of Economics and Management Science, 4, $141-183$.

Merton, R. C., 1974, "On the Pricing of Corporate Debt: The Risk Structure of Interest Rates," Journal of Finance, 29(1), 449-470. 
Merton, R. C., 1976, “Option Pricing When Underlying Stock Returns Are Discontinuous,” Journal of Financial Economics, 3(1), 125-144.

Newey, W. K., and K. D. West, 1987, “A Simple, Positive Semi-Definite, Heteroskedasticity and Autocorrelation Consistent Covariance Matrix," Econometrica, 55(3), 703-708.

Rubinstein, M., 1983, “Displaced Diffusion Option Pricing,” Journal of Finance, 38(1), 213-217. 
Table 1

List of companies used in our study

Entries list the equity ticker, cusip, and the name of the companies that are used in our study.

\begin{tabular}{lll}
\hline Equity Ticker & Cusip Number & Company Name \\
& & \\
AMR & 00176510 & AMR Corp \\
CTB & 21683110 & Cooper Tire \& Ribber \\
DDS & 25406710 & Dillard's Inc. \\
EK & 27746110 & Eastman Kodak Co \\
F & 34537086 & Ford Motor Co \\
GM & 37044210 & General Motors Corp \\
GT & 38255010 & Goodyear Tire \& Rubber Co \\
KBH & 48666 K10 & KB Home \\
& & \\
\hline
\end{tabular}


Table 2

Summary statistics of default probabilities

Entries report the mean, standard deviation (Std), minimum (Min), maximum (Max), daily autocorrelation (Auto) of companies' one-year default probabilities (in percentage points) estimated from the American put spreads in the left panel and from the CDS spreads in the right panel. The left panel reports the crosscorrelation $(\rho)$ between the two time series for each company.

\begin{tabular}{|c|c|c|c|c|c|c|c|c|c|c|c|}
\hline \multirow[t]{2}{*}{ Ticker } & \multicolumn{5}{|c|}{ From American put spreads } & \multicolumn{5}{|c|}{ From CDS spreads } & \multirow[t]{2}{*}{$\rho$} \\
\hline & Mean & Std & Min & Max & Auto & Mean & Std & Min & Max & Auto & \\
\hline \multicolumn{12}{|c|}{ One-year default probabilities: } \\
\hline AMR & 5.199 & 3.240 & 1.083 & 14.603 & 0.973 & 12.095 & 9.317 & 1.877 & 30.116 & 0.996 & 0.852 \\
\hline CTB & 2.817 & 1.369 & 1.135 & 10.006 & 0.891 & 1.865 & 1.580 & 0.133 & 8.911 & 0.988 & 0.744 \\
\hline DDS & 2.058 & 0.911 & 0.578 & 4.194 & 0.946 & 1.010 & 0.654 & 0.118 & 2.840 & 0.986 & 0.696 \\
\hline EK & 2.056 & 0.950 & 0.534 & 6.151 & 0.966 & 1.014 & 0.511 & 0.250 & 2.713 & 0.987 & 0.762 \\
\hline $\mathrm{F}$ & 4.655 & 1.841 & 1.092 & 10.693 & 0.953 & 5.386 & 3.588 & 1.120 & 15.211 & 0.993 & 0.831 \\
\hline GM & 3.871 & 2.943 & 0.920 & 14.552 & 0.974 & 7.333 & 6.384 & 1.242 & 22.766 & 0.996 & 0.944 \\
\hline GT & 3.180 & 1.432 & 0.669 & 8.382 & 0.966 & 2.351 & 1.150 & 0.263 & 6.288 & 0.988 & 0.886 \\
\hline $\mathrm{KBH}$ & 1.233 & 0.599 & 0.349 & 3.688 & 0.942 & 0.815 & 0.398 & 0.205 & 2.683 & 0.966 & 0.207 \\
\hline \multicolumn{12}{|c|}{ Two-year default probabilities: } \\
\hline AMR & 10.755 & 6.324 & 2.197 & 28.449 & 0.981 & 26.183 & 16.795 & 5.911 & 52.788 & 0.997 & 0.937 \\
\hline СТВ & 5.384 & 2.582 & 2.144 & 19.010 & 0.885 & 4.932 & 3.396 & 0.896 & 17.348 & 0.993 & 0.688 \\
\hline DDS & 4.246 & 1.534 & 1.353 & 7.491 & 0.924 & 3.210 & 1.517 & 1.095 & 6.826 & 0.990 & 0.665 \\
\hline EK & 4.166 & 1.769 & 1.461 & 11.925 & 0.950 & 3.397 & 1.487 & 1.244 & 7.795 & 0.991 & 0.854 \\
\hline $\mathrm{F}$ & 9.204 & 3.764 & 2.065 & 20.242 & 0.954 & 14.336 & 7.239 & 3.893 & 28.108 & 0.994 & 0.850 \\
\hline GM & 8.694 & 6.251 & 2.669 & 27.343 & 0.983 & 17.489 & 11.466 & 5.265 & 41.790 & 0.996 & 0.935 \\
\hline GT & 6.451 & 2.590 & 1.270 & 13.383 & 0.970 & 6.546 & 2.558 & 1.597 & 13.889 & 0.990 & 0.853 \\
\hline $\mathrm{KBH}$ & 3.117 & 1.059 & 1.063 & 5.794 & 0.940 & 2.517 & 0.974 & 1.017 & 6.329 & 0.975 & 0.352 \\
\hline \multicolumn{12}{|c|}{ Three-year default probabilities: } \\
\hline AMR & 15.661 & 8.819 & 3.277 & 39.477 & 0.980 & 38.026 & 19.427 & 12.571 & 71.372 & 0.997 & 0.957 \\
\hline СТВ & 7.953 & 3.737 & 3.198 & 27.114 & 0.885 & 9.072 & 5.329 & 2.395 & 25.038 & 0.995 & 0.651 \\
\hline DDS & 6.298 & 2.250 & 2.023 & 11.023 & 0.919 & 7.184 & 2.215 & 3.922 & 11.977 & 0.990 & 0.622 \\
\hline EK & 6.133 & 2.571 & 1.941 & 17.342 & 0.943 & 7.098 & 2.524 & 3.108 & 13.837 & 0.992 & 0.862 \\
\hline $\mathrm{F}$ & 13.428 & 5.408 & 3.021 & 28.771 & 0.953 & 24.482 & 8.663 & 7.485 & 39.043 & 0.992 & 0.850 \\
\hline GM & 12.787 & 8.703 & 3.977 & 38.146 & 0.980 & 27.504 & 12.777 & 9.702 & 51.941 & 0.995 & 0.879 \\
\hline GT & 9.534 & 3.776 & 1.899 & 19.387 & 0.968 & 12.958 & 4.534 & 3.971 & 24.689 & 0.992 & 0.847 \\
\hline $\mathrm{KBH}$ & 4.891 & 1.933 & 1.590 & 9.461 & 0.925 & 5.242 & 1.763 & 2.289 & 12.551 & 0.979 & 0.321 \\
\hline
\end{tabular}


Table 3

Regressing default probabilities from American put spreads on default probabilities from the CDS

Entries report the estimates, Newey-West $t$-statistics (in parentheses), and R-squares $\left(R^{2}\right)$ from regressing the one-year default probabilities computed from American put spreads on the one-year default probabilities computed from the CDS spreads written on the same reference company,

$$
\mathbb{Q}_{t}^{o}=a+b \mathbb{Q}_{t}^{c}+e_{t}
$$

The $t$-statistics of the intercept are computed against the null hypothesis of zero and the $t$-statistics of the slope are computed against the null hypothesis of one.

\begin{tabular}{|c|c|c|c|c|c|}
\hline \multirow[t]{2}{*}{ Ticker } & \multicolumn{2}{|c|}{ Intercept } & \multicolumn{2}{|c|}{ Slope } & \multirow[t]{2}{*}{$R^{2}$} \\
\hline & \multicolumn{4}{|c|}{ One-year default probabilities: } & \\
\hline AMR & 1.614 & $(5.27)$ & 0.296 & $(-16.41)$ & 0.726 \\
\hline СТВ & 1.614 & $(10.07)$ & 0.645 & $(-4.87)$ & 0.554 \\
\hline DDS & 1.078 & $(6.43)$ & 0.970 & $(-0.22)$ & 0.484 \\
\hline EK & 0.622 & $(3.05)$ & 1.415 & $(2.16)$ & 0.580 \\
\hline $\mathrm{F}$ & 2.359 & $(7.81)$ & 0.426 & $(-13.72)$ & 0.690 \\
\hline GM & 0.681 & $(3.47)$ & 0.435 & $(-17.11)$ & 0.891 \\
\hline GT & 0.587 & $(3.21)$ & 1.103 & $(1.34)$ & 0.785 \\
\hline \multirow[t]{2}{*}{$\mathrm{KBH}$} & 0.979 & $(5.12)$ & 0.312 & $(-4.11)$ & 0.043 \\
\hline & \multicolumn{4}{|c|}{ Two-year default probabilities: } & \\
\hline AMR & 1.521 & $(3.54)$ & 0.353 & $(-24.75)$ & 0.877 \\
\hline СТВ & 2.804 & $(5.88)$ & 0.523 & $(-4.99)$ & 0.473 \\
\hline DDS & 2.088 & $(5.31)$ & 0.672 & $(-3.42)$ & 0.442 \\
\hline EK & 0.716 & $(2.29)$ & 1.016 & $(0.17)$ & 0.729 \\
\hline $\mathrm{F}$ & 2.871 & $(3.96)$ & 0.442 & $(-15.46)$ & 0.722 \\
\hline GM & -0.223 & $(-0.36)$ & 0.510 & $(-11.22)$ & 0.874 \\
\hline GT & 0.798 & $(1.77)$ & 0.864 & $(-1.99)$ & 0.728 \\
\hline \multirow[t]{2}{*}{$\mathrm{KBH}$} & 2.153 & $(5.29)$ & 0.383 & $(-4.26)$ & 0.124 \\
\hline & \multicolumn{4}{|c|}{ Three-year default probabilities: } & \\
\hline AMR & -0.866 & $(-1.09)$ & 0.435 & $(-23.84)$ & 0.917 \\
\hline CTB & 3.812 & $(4.52)$ & 0.457 & $(-5.71)$ & 0.424 \\
\hline DDS & 1.760 & $(2.15)$ & 0.632 & $(-3.44)$ & 0.387 \\
\hline EK & -0.098 & $(-0.21)$ & 0.878 & $(-1.77)$ & 0.743 \\
\hline $\mathrm{F}$ & 0.445 & $(0.42)$ & 0.530 & $(-12.85)$ & 0.722 \\
\hline GM & -3.689 & $(-2.28)$ & 0.599 & $(-5.67)$ & 0.773 \\
\hline GT & 0.399 & $(0.63)$ & 0.705 & $(-5.81)$ & 0.717 \\
\hline $\mathrm{KBH}$ & 3.047 & $(3.43)$ & 0.352 & $(-3.92)$ & 0.103 \\
\hline
\end{tabular}


Table 4

Predicting future movements at daily horizon based on cross-market deviations

Entries report the estimates, Newey-West $t$-statistics (in parentheses), and R-squares $\left(R^{2}\right)$ from the following regressions,

$$
\Delta \mathbb{Q}_{t+\Delta t}^{o}=a^{o}+b^{o}\left(\mathbb{Q}_{t}^{o}-c \mathbb{Q}_{t}^{c}\right)+e_{t+\Delta t}^{o}, \quad \Delta \mathbb{Q}_{t+\Delta t}^{c}=a^{c}+b^{c}\left(\mathbb{Q}_{t}^{o}-c \mathbb{Q}_{t}^{c}\right)+e_{t+\Delta t}^{c},
$$

where $\Delta \mathbb{Q}_{t+\Delta t}$ denotes future changes over a one-day horizon, which are predicted by the deviations between the estimates from the two markets.

\begin{tabular}{|c|c|c|c|c|c|c|c|c|c|c|c|c|}
\hline Ticker & & $a^{o}$ & & $b^{o}$ & $R^{2}$ & & $a^{c}$ & & $b^{c}$ & $R^{2}$ & & $c$ \\
\hline \multicolumn{13}{|c|}{ One-year default probabilities: } \\
\hline AMR & 0.139 & $(2.46)$ & -0.095 & $(-2.38)$ & 0.047 & -0.060 & $(-1.38)$ & 0.022 & $(1.40)$ & 0.003 & 0.304 & $(10.19)$ \\
\hline СТВ & 0.381 & ( 4.62$)$ & -0.229 & $(-5.86)$ & 0.108 & -0.021 & $(-0.93)$ & 0.014 & $(1.38)$ & 0.003 & 0.617 & $(11.95)$ \\
\hline DDS & 0.106 & $(2.57)$ & -0.097 & $(-3.08)$ & 0.045 & -0.007 & $(-0.53)$ & 0.008 & $(0.77)$ & 0.003 & 0.931 & ( 6.86$)$ \\
\hline EK & 0.049 & ( 2.93$)$ & -0.080 & $(-4.27)$ & 0.042 & -0.003 & $(-0.65)$ & 0.005 & $(0.88)$ & 0.001 & 1.441 & ( 8.49$)$ \\
\hline $\mathrm{F}$ & 0.342 & ( 4.28$)$ & -0.140 & $(-4.34)$ & 0.069 & 0.036 & $(0.79)$ & -0.013 & $(-0.77)$ & 0.001 & 0.413 & ( 11.25$)$ \\
\hline GM & 0.118 & ( 2.87 ) & -0.165 & $(-5.51)$ & 0.061 & -0.075 & $(-3.15)$ & 0.109 & ( 3.57$)$ & 0.041 & 0.431 & (23.99) \\
\hline GT & 0.076 & (3.58) & -0.157 & $(-6.20)$ & 0.082 & -0.007 & $(-0.80)$ & 0.011 & $(0.93)$ & 0.002 & 1.136 & $(18.80)$ \\
\hline $\mathrm{KBH}$ & 0.058 & $(2.19)$ & -0.060 & $(-2.14)$ & 0.030 & 0.001 & $(0.10)$ & 0.002 & $(0.44)$ & 0.000 & 0.353 & ( 1.37$)$ \\
\hline \multicolumn{13}{|c|}{ Two-year default probabilities: } \\
\hline AMR & 0.176 & (3.04) & -0.132 & $(-2.43)$ & 0.066 & -0.074 & $(-1.38)$ & 0.012 & $(0.49)$ & 0.001 & 0.353 & ( 19.94$)$ \\
\hline СТВ & 0.606 & ( 5.06$)$ & -0.207 & $(-6.14)$ & 0.099 & -0.008 & $(-0.27)$ & 0.005 & $(0.68)$ & 0.001 & 0.499 & $(9.85)$ \\
\hline DDS & 0.286 & ( 4.18$)$ & -0.130 & $(-4.37)$ & 0.062 & -0.014 & $(-0.71)$ & 0.008 & ( 1.19$)$ & 0.003 & 0.641 & $(7.42)$ \\
\hline EK & 0.126 & ( 3.16$)$ & -0.170 & $(-4.13)$ & 0.083 & -0.004 & $(-0.43)$ & 0.007 & $(0.86)$ & 0.001 & 1.009 & ( 16.34$)$ \\
\hline $\mathrm{F}$ & 0.464 & $(2.90)$ & -0.154 & $(-3.33)$ & 0.078 & 0.012 & $(0.27)$ & -0.001 & $(-0.13)$ & 0.000 & 0.434 & ( 13.91$)$ \\
\hline GM & -0.022 & $(-0.44)$ & -0.098 & $(-4.11)$ & 0.038 & 0.019 & $(0.40)$ & 0.066 & ( 2.19$)$ & 0.034 & 0.510 & $(18.41)$ \\
\hline GT & 0.047 & $(1.71)$ & -0.099 & $(-4.37)$ & 0.050 & -0.011 & $(-0.52)$ & 0.009 & $(0.86)$ & 0.001 & 0.904 & $(12.11)$ \\
\hline KBH & 0.148 & ( 4.02$)$ & -0.069 & $(-3.96)$ & 0.034 & -0.002 & $(-0.07)$ & 0.004 & $(0.39)$ & 0.000 & 0.390 & $(2.30)$ \\
\hline \multicolumn{13}{|c|}{ Three-year default probabilities: } \\
\hline AMR & -0.216 & $(-1.87)$ & -0.203 & $(-3.57)$ & 0.102 & -0.016 & $(-0.28)$ & 0.042 & ( 1.62 ) & 0.008 & 0.435 & ( 32.04$)$ \\
\hline СТВ & 0.764 & $(4.74)$ & -0.191 & $(-5.83)$ & 0.092 & -0.007 & $(-0.17)$ & 0.004 & $(0.58)$ & 0.001 & 0.436 & $(8.65)$ \\
\hline DDS & 0.254 & $(3.47)$ & -0.125 & $(-4.15)$ & 0.060 & -0.009 & $(-0.42)$ & 0.007 & ( 1.12$)$ & 0.003 & 0.596 & ( 6.46$)$ \\
\hline EK & -0.003 & $(-0.08)$ & -0.206 & $(-4.86)$ & 0.099 & 0.005 & $(0.36)$ & 0.010 & $(1.52)$ & 0.002 & 0.867 & $(18.68)$ \\
\hline $\mathrm{F}$ & 0.123 & $(1.23)$ & -0.154 & $(-3.62)$ & 0.077 & 0.014 & $(0.34)$ & 0.002 & $(0.22)$ & 0.000 & 0.518 & $(14.10)$ \\
\hline GM & -0.234 & $(-2.62)$ & -0.069 & $(-3.15)$ & 0.030 & 0.082 & ( 1.19$)$ & 0.022 & $(1.57)$ & 0.011 & 0.588 & $(10.46)$ \\
\hline GT & -0.002 & $(-0.05)$ & -0.098 & $(-4.24)$ & 0.048 & -0.011 & $(-0.43)$ & 0.009 & $(0.84)$ & 0.001 & 0.731 & ( 11.40$)$ \\
\hline KBH & 0.250 & $(3.45)$ & -0.083 & $(-3.76)$ & 0.042 & 0.002 & $(0.06)$ & 0.003 & $(0.30)$ & 0.000 & 0.363 & ( 2.40$)$ \\
\hline
\end{tabular}


Table 5

Predicting future movements at weekly horizon based on cross-market deviations

Entries report the estimates, Newey-West $t$-statistics (in parentheses), and R-squares $\left(R^{2}\right)$ from the following regressions,

$$
\Delta \mathbb{Q}_{t+\Delta t}^{o}=a^{o}+b^{o}\left(\mathbb{Q}_{t}^{o}-c \mathbb{Q}_{t}^{c}\right)+e_{t+\Delta t}^{o}, \quad \Delta \mathbb{Q}_{t+\Delta t}^{c}=a^{c}+b^{c}\left(\mathbb{Q}_{t}^{o}-c \mathbb{Q}_{t}^{c}\right)+e_{t+\Delta t}^{c},
$$

where $\Delta \mathbb{Q}_{t+\Delta t}$ denotes future changes over a one-week horizon, which are predicted by the deviations between the estimates from the two markets.

\begin{tabular}{|c|c|c|c|c|c|c|c|c|c|c|c|c|}
\hline Ticker & & $a^{o}$ & & $b^{o}$ & $R^{2}$ & & $a^{c}$ & & $b^{c}$ & $R^{2}$ & & $c$ \\
\hline \multicolumn{13}{|c|}{ One-year default probabilities: } \\
\hline AMR & 0.138 & ( 1.48$)$ & -0.137 & $(-1.88)$ & 0.064 & -0.216 & $(-1.30)$ & 0.062 & $(0.90)$ & 0.007 & 0.325 & ( 10.68$)$ \\
\hline СТВ & 0.672 & (3.50) & -0.398 & $(-3.39)$ & 0.141 & -0.160 & $(-1.98)$ & 0.106 & (2.79) & 0.026 & 0.651 & $(14.10)$ \\
\hline DDS & 0.206 & ( 2.69$)$ & -0.203 & $(-3.48)$ & 0.100 & -0.046 & $(-1.07)$ & 0.048 & $(1.31)$ & 0.020 & 1.033 & $(11.54)$ \\
\hline EK & 0.201 & $(3.25)$ & -0.245 & $(-3.82)$ & 0.115 & 0.002 & $(0.07)$ & 0.001 & $(0.04)$ & 0.000 & 1.255 & $(12.11)$ \\
\hline $\mathrm{F}$ & 0.803 & $(4.14)$ & -0.293 & $(-4.33)$ & 0.135 & 0.201 & ( 1.03$)$ & -0.065 & $(-1.01)$ & 0.005 & 0.372 & $(12.05)$ \\
\hline GM & 0.113 & $(1.15)$ & -0.219 & $(-3.02)$ & 0.053 & -0.196 & $(-1.68)$ & 0.463 & ( 3.98$)$ & 0.119 & 0.465 & ( 34.92$)$ \\
\hline GT & 0.137 & $(2.70)$ & -0.324 & $(-5.88)$ & 0.149 & -0.046 & $(-1.16)$ & 0.086 & $(1.50)$ & 0.018 & 1.156 & ( 24.62) \\
\hline $\mathrm{KBH}$ & 0.201 & ( 3.04 ) & -0.160 & $(-3.26)$ & 0.081 & 0.010 & $(0.29)$ & 0.003 & $(0.17)$ & 0.000 & 0.002 & $(0.01)$ \\
\hline \multicolumn{13}{|c|}{ Two-year default probabilities: } \\
\hline AMR & 0.223 & ( 2.11$)$ & -0.253 & $(-2.80)$ & 0.126 & -0.354 & $(-1.71)$ & 0.060 & $(0.68)$ & 0.005 & 0.363 & ( 23.63$)$ \\
\hline СТВ & 1.131 & (3.80) & -0.355 & $(-3.43)$ & 0.128 & -0.041 & $(-0.23)$ & 0.022 & $(0.51)$ & 0.002 & 0.492 & ( 10.38$)$ \\
\hline DDS & 0.584 & ( 4.64 ) & -0.262 & $(-5.50)$ & 0.130 & -0.079 & $(-1.06)$ & 0.040 & ( 1.55$)$ & 0.012 & 0.645 & $(10.63)$ \\
\hline EK & 0.347 & ( 3.63 ) & -0.428 & $(-5.40)$ & 0.198 & 0.003 & $(0.05)$ & 0.015 & $(0.39)$ & 0.001 & 1.002 & ( 25.31) \\
\hline $\mathrm{F}$ & 0.982 & $(3.21)$ & -0.295 & $(-3.78)$ & 0.142 & 0.006 & $(0.03)$ & 0.018 & $(0.39)$ & 0.001 & 0.421 & ( 15.33$)$ \\
\hline GM & -0.107 & $(-0.75)$ & -0.134 & $(-2.10)$ & 0.030 & 0.213 & $(0.93)$ & 0.201 & (2.19) & 0.050 & 0.547 & $(21.50)$ \\
\hline GT & 0.042 & $(0.46)$ & -0.253 & $(-4.10)$ & 0.122 & -0.041 & $(-0.44)$ & 0.074 & ( 1.34 ) & 0.014 & 0.951 & ( 18.65 ) \\
\hline KBH & 0.415 & ( 4.08$)$ & -0.181 & $(-4.37)$ & 0.088 & 0.024 & $(0.19)$ & 0.002 & $(0.04)$ & 0.000 & 0.316 & ( 2.61$)$ \\
\hline \multicolumn{13}{|c|}{ Three-year default probabilities: } \\
\hline AMR & -0.517 & $(-2.06)$ & -0.348 & $(-3.91)$ & 0.152 & -0.071 & $(-0.23)$ & 0.183 & ( 1.76$)$ & 0.035 & 0.441 & ( 36.73 ) \\
\hline СТВ & 1.477 & ( 3.96 ) & -0.326 & $(-3.56)$ & 0.119 & -0.022 & $(-0.09)$ & 0.016 & $(0.39)$ & 0.001 & 0.417 & ( 8.89$)$ \\
\hline DDS & 0.527 & (3.59) & -0.245 & $(-5.16)$ & 0.121 & -0.067 & $(-0.78)$ & 0.039 & ( 1.47 ) & 0.013 & 0.589 & $(8.88)$ \\
\hline EK & 0.022 & $(0.22)$ & -0.516 & $(-6.42)$ & 0.240 & 0.026 & $(0.42)$ & 0.031 & $(0.92)$ & 0.003 & 0.868 & $(29.50)$ \\
\hline $\mathrm{F}$ & 0.352 & ( 1.49 ) & -0.287 & $(-3.84)$ & 0.133 & 0.071 & $(0.36)$ & 0.037 & $(0.82)$ & 0.003 & 0.508 & ( 16.18$)$ \\
\hline GM & -0.410 & $(-1.62)$ & -0.102 & $(-2.15)$ & 0.029 & 0.382 & ( 1.26$)$ & 0.079 & ( 1.41 ) & 0.021 & 0.617 & (12.09) \\
\hline GT & -0.080 & $(-0.62)$ & -0.238 & $(-3.64)$ & 0.111 & -0.027 & $(-0.23)$ & 0.047 & $(0.93)$ & 0.006 & 0.753 & ( 16.25 ) \\
\hline $\mathrm{KBH}$ & 0.631 & $(4.15)$ & -0.221 & $(-4.70)$ & 0.111 & 0.024 & $(0.14)$ & 0.009 & $(0.22)$ & 0.001 & 0.377 & ( 3.73$)$ \\
\hline
\end{tabular}


Table 6

Predicting future movements at a monthly horizon based on cross-market deviations

Entries report the estimates, Newey-West $t$-statistics (in parentheses), and R-squares $\left(R^{2}\right)$ from the following regressions,

$$
\Delta \mathbb{Q}_{t+\Delta t}^{o}=a^{o}+b^{o}\left(\mathbb{Q}_{t}^{o}-c \mathbb{Q}_{t}^{c}\right)+e_{t+\Delta t}^{o}, \quad \Delta \mathbb{Q}_{t+\Delta t}^{c}=a^{c}+b^{c}\left(\mathbb{Q}_{t}^{o}-c \mathbb{Q}_{t}^{c}\right)+e_{t+\Delta t}^{c},
$$

where $\Delta \mathbb{Q}_{t+\Delta t}$ denotes future changes over a 30-day horizon, which are predicted by the deviations between the estimates from the two markets.

\begin{tabular}{|c|c|c|c|c|c|c|c|c|c|c|c|c|}
\hline Ticker & & $a^{o}$ & & $b^{o}$ & $R^{2}$ & & $a^{c}$ & & $b^{c}$ & $R^{2}$ & & $c$ \\
\hline \multicolumn{13}{|c|}{ One-year default probabilities: } \\
\hline AMR & 0.382 & $(1.31)$ & -0.365 & $(-1.75)$ & 0.149 & -0.779 & $(-1.24)$ & 0.061 & $(0.20)$ & 0.001 & 0.290 & $(12.58)$ \\
\hline СТВ & 1.032 & (3.16) & -0.213 & $(-2.76)$ & 0.135 & 0.762 & $(2.07)$ & -0.170 & $(-2.03)$ & 0.102 & -0.866 & $(-3.14)$ \\
\hline DDS & 0.284 & ( 1.94$)$ & -0.314 & $(-2.73)$ & 0.114 & -0.173 & $(-1.23)$ & 0.165 & $(1.29)$ & 0.053 & 1.069 & $(15.17)$ \\
\hline EK & 0.817 & (3.65) & -0.790 & $(-4.98)$ & 0.349 & 0.132 & $(1.22)$ & -0.136 & $(-2.01)$ & 0.057 & 1.047 & $(18.28)$ \\
\hline $\mathrm{F}$ & 2.302 & (3.84) & -0.594 & $(-3.88)$ & 0.271 & 1.846 & $(2.51)$ & -0.479 & $(-2.92)$ & 0.090 & 0.192 & $(6.11)$ \\
\hline GM & 0.038 & $(0.12)$ & -0.081 & $(-0.48)$ & 0.003 & 0.183 & $(0.34)$ & 1.012 & (3.62) & 0.157 & 0.545 & $(32.88)$ \\
\hline GT & 0.500 & $(2.61)$ & -0.653 & $(-2.95)$ & 0.166 & -0.264 & $(-1.91)$ & 0.208 & ( 1.13$)$ & 0.022 & 0.980 & $(25.07)$ \\
\hline $\mathrm{KBH}$ & 0.612 & $(3.57)$ & -0.255 & $(-3.60)$ & 0.173 & 0.333 & $(1.95)$ & -0.137 & $(-2.22)$ & 0.095 & -1.352 & $(-6.35)$ \\
\hline \multicolumn{13}{|c|}{ Two-year default probabilities: } \\
\hline AMR & 0.901 & ( 2.98$)$ & -0.659 & $(-5.52)$ & 0.285 & -0.988 & $(-1.50)$ & -0.185 & $(-0.89)$ & 0.011 & 0.334 & ( 29.61$)$ \\
\hline СТВ & 2.711 & (3.20) & -0.579 & $(-3.06)$ & 0.198 & 0.424 & $(0.46)$ & -0.097 & $(-0.50)$ & 0.008 & 0.210 & $(4.34)$ \\
\hline DDS & 1.108 & (3.32) & -0.418 & $(-4.53)$ & 0.148 & -0.457 & $(-1.68)$ & 0.164 & ( 1.79$)$ & 0.044 & 0.488 & $(9.40)$ \\
\hline EK & 1.244 & $(5.27)$ & -0.916 & $(-10.68)$ & 0.371 & 0.220 & $(1.22)$ & -0.165 & $(-1.71)$ & 0.031 & 0.842 & ( 27.91$)$ \\
\hline $\mathrm{F}$ & 3.237 & (4.10) & -0.448 & $(-4.32)$ & 0.214 & 1.666 & ( 1.24$)$ & -0.212 & $(-1.43)$ & 0.025 & 0.181 & ( 4.47$)$ \\
\hline GM & 0.139 & $(0.31)$ & 0.031 & $(0.21)$ & 0.001 & 2.200 & $(2.16)$ & 0.750 & (3.49) & 0.163 & 0.652 & (30.01) \\
\hline GT & 1.401 & $(2.23)$ & -0.607 & $(-3.68)$ & 0.198 & 0.055 & $(0.09)$ & -0.103 & $(-0.65)$ & 0.006 & 0.618 & ( 14.35$)$ \\
\hline $\mathrm{KBH}$ & 1.374 & $(3.13)$ & -0.252 & $(-3.14)$ & 0.149 & 1.480 & $(2.30)$ & -0.261 & $(-2.60)$ & 0.177 & -0.954 & $(-6.06)$ \\
\hline \multicolumn{13}{|c|}{ Three-year default probabilities: } \\
\hline AMR & -0.835 & $(-1.52)$ & -0.771 & $(-6.96)$ & 0.262 & -1.349 & $(-1.28)$ & 0.058 & $(0.32)$ & 0.001 & 0.420 & ( 33.64 ) \\
\hline СТВ & 3.605 & ( 3.07$)$ & -0.616 & $(-3.00)$ & 0.208 & 0.114 & $(0.09)$ & -0.013 & $(-0.07)$ & 0.000 & 0.283 & $(7.29)$ \\
\hline DDS & 1.382 & ( 3.13 ) & -0.389 & $(-4.69)$ & 0.148 & -0.488 & $(-1.30)$ & 0.132 & $(1.52)$ & 0.034 & 0.375 & ( 6.42$)$ \\
\hline EK & 0.924 & ( 3.51$)$ & -1.002 & $(-11.39)$ & 0.403 & 0.156 & $(0.70)$ & -0.153 & $(-1.77)$ & 0.022 & 0.742 & ( 30.61$)$ \\
\hline $\mathrm{F}$ & 4.320 & (3.93) & -0.314 & $(-3.88)$ & 0.177 & 2.976 & ( 1.64 ) & -0.201 & $(-1.86)$ & 0.052 & 0.040 & $(0.55)$ \\
\hline GM & -0.048 & $(-0.05)$ & -0.009 & $(-0.08)$ & 0.000 & 4.496 & ( 2.24$)$ & 0.341 & $(2.53)$ & 0.121 & 0.917 & ( 16.94$)$ \\
\hline GT & 1.319 & ( 1.87$)$ & -0.635 & $(-3.70)$ & 0.221 & 0.004 & $(0.01)$ & -0.136 & $(-0.90)$ & 0.010 & 0.562 & (15.28) \\
\hline $\mathrm{KBH}$ & 1.783 & $(4.03)$ & -0.626 & $(-5.06)$ & 0.308 & 0.179 & $(0.31)$ & -0.019 & $(-0.14)$ & 0.000 & 0.407 & $(7.31)$ \\
\hline
\end{tabular}


Table 7

Summary statistics of unit recovery claims

Entries report the mean, standard deviation (Std), minimum (Min), maximum (Max) of unit recovery claims extracted for the American put options $\left(U^{o}\right)$ and from CDS markets $\left(U^{c}\right)$ as well as their cross-correlations $(\rho)$ and co-movement regressions.

\begin{tabular}{|c|c|c|c|c|c|c|c|c|c|c|c|c|c|c|}
\hline \multirow[t]{2}{*}{ Ticker } & \multicolumn{4}{|c|}{$U^{o}$} & \multicolumn{4}{|c|}{$U^{c}$} & \multirow[t]{2}{*}{$\rho$} & \multicolumn{5}{|c|}{$U_{t}^{o}=a+b U_{t}^{c}+e_{t}$} \\
\hline & Mean & Std & Min & Max & Mean & Std & Min & Max & & & $\bar{a}$ & & $b$ & $R^{2}$ \\
\hline AMR & 0.116 & 0.073 & 0.020 & 0.300 & 0.264 & 0.164 & 0.055 & 0.566 & 0.934 & 0.007 & ( 1.21$)$ & 0.413 & $(-17.71)$ & 0.872 \\
\hline СТВ & 0.087 & 0.039 & 0.020 & 0.205 & 0.053 & 0.042 & 0.006 & 0.217 & 0.364 & 0.069 & $(5.80)$ & 0.339 & $(-4.95)$ & 0.133 \\
\hline DDS & 0.063 & 0.026 & 0.022 & 0.130 & 0.033 & 0.018 & 0.009 & 0.079 & 0.716 & 0.028 & ( 4.36 ) & 1.046 & $(0.28)$ & 0.513 \\
\hline EK & 0.043 & 0.019 & 0.013 & 0.090 & 0.038 & 0.019 & 0.011 & 0.084 & 0.868 & 0.011 & ( 3.83 ) & 0.836 & $(-2.53)$ & 0.754 \\
\hline $\mathrm{F}$ & 0.103 & 0.044 & 0.020 & 0.235 & 0.138 & 0.066 & 0.035 & 0.274 & 0.804 & 0.029 & (2.81) & 0.531 & $(-7.77)$ & 0.646 \\
\hline $\mathrm{KBH}$ & 0.048 & 0.038 & 0.010 & 0.160 & 0.026 & 0.011 & 0.009 & 0.049 & 0.777 & -0.025 & $(-2.28)$ & 2.786 & $(3.25)$ & 0.604 \\
\hline
\end{tabular}


Table 8

Predicting future movements on unit recovery claims based on cross-market deviations

Entries report the estimates, Newey-West $t$-statistics (in parentheses), and R-squares $\left(R^{2}\right)$ from the following regression that predicts future movements in the unit recovery claim synthesized by American puts $\left(U^{o}\right)$ based on its deviations from the CDS market valuations,

$$
\Delta U_{t+\Delta t}^{o}=\alpha+\beta\left(U_{t}^{o}-b U_{t}^{c}\right)+e_{t},
$$

where forecasting horizons $(\Delta t)$ are at one, seven, and 30 days and the cointegrating coefficients $b$ are obtained from the level regressions in Table 7.

\begin{tabular}{|c|c|c|c|c|c|c|c|c|c|c|c|c|c|c|c|}
\hline \multirow{3}{*}{$\begin{array}{l}\text { Ticker } \\
\text { AMR }\end{array}$} & \multicolumn{5}{|c|}{ One days } & \multicolumn{5}{|c|}{ Seven days } & \multicolumn{5}{|c|}{30 days } \\
\hline & \multicolumn{2}{|c|}{$\alpha$} & \multicolumn{2}{|c|}{$\beta$} & \multirow{2}{*}{$\begin{array}{r}R^{2} \\
0.034\end{array}$} & \multicolumn{2}{|r|}{$\alpha$} & \multicolumn{2}{|c|}{$\beta$} & \multirow{2}{*}{$\begin{array}{r}R^{2} \\
0.079\end{array}$} & \multicolumn{2}{|r|}{$\alpha$} & \multicolumn{2}{|c|}{$\beta$} & \multirow{2}{*}{$\begin{array}{r}R^{2} \\
0.241\end{array}$} \\
\hline & -0.000 & $(-0.08)$ & -0.070 & $(-2.75)$ & & -0.001 & $(-0.99)$ & -0.175 & $(-2.48)$ & & -0.006 & $(-1.20)$ & -0.598 & $(-3.76)$ & \\
\hline СТB & 0.001 & $(1.51)$ & -0.015 & $(-1.44)$ & 0.005 & 0.005 & $(1.33)$ & -0.056 & $(-1.20)$ & 0.015 & 0.012 & $(1.17)$ & -0.144 & $(-1.07)$ & 0.029 \\
\hline DDS & 0.000 & ( 1.81$)$ & -0.022 & $(-2.66)$ & 0.012 & 0.002 & $(1.53)$ & -0.088 & $(-2.55)$ & 0.052 & 0.004 & $(1.26)$ & -0.290 & $(-3.10)$ & 0.159 \\
\hline EK & 0.001 & $(4.84)$ & -0.093 & $(-4.36)$ & 0.053 & 0.003 & ( 5.12$)$ & -0.297 & $(-6.03)$ & 0.172 & 0.011 & $(4.46)$ & -0.969 & $(-9.93)$ & 0.422 \\
\hline $\mathrm{F}$ & 0.002 & $(3.23)$ & -0.077 & $(-2.89)$ & 0.050 & 0.006 & $(2.74)$ & -0.201 & $(-2.63)$ & 0.111 & 0.017 & $(2.72)$ & -0.571 & $(-3.34)$ & 0.227 \\
\hline GM & -0.001 & $(-1.60)$ & -0.122 & $(-3.42)$ & 0.051 & -0.001 & $(-0.71)$ & -0.162 & $(-2.65)$ & 0.040 & -0.002 & $(-0.41)$ & -0.226 & $(-1.03)$ & 0.021 \\
\hline GT & 0.000 & $(1.00)$ & -0.063 & $(-3.66)$ & 0.032 & 0.001 & $(0.53)$ & -0.184 & $(-2.50)$ & 0.077 & 0.001 & $(0.22)$ & -0.599 & $(-2.33)$ & 0.192 \\
\hline $\mathrm{KBH}$ & -0.000 & $(-1.14)$ & -0.008 & $(-1.29)$ & 0.002 & -0.000 & $(-0.32)$ & -0.004 & $(-0.10)$ & 0.000 & -0.001 & $(-0.29)$ & 0.043 & $(0.53)$ & 0.007 \\
\hline
\end{tabular}


Table 9

Default probabilities estimated from a structural model

Entries report the mean, standard deviation (Std), minimum (Min), maximum (Max), daily autocorrelation (Auto) of companies' one-year default probabilities (in percentage points) estimated from Merton (1974)'s structural model. The computations uses the stock price as the per share equity value and net debt per share as the per share debt face value, and computes the firm value assuming equality between the market and the face value of the debt. To compute firm volatility, the left panel uses one-standard deviation out-of-money stock option implied volatility as input whereas the right panel uses at-the-money stock option implied volatility as input.

\begin{tabular}{|c|c|c|c|c|c|c|c|c|c|c|c|c|}
\hline \multirow[t]{2}{*}{ Ticker } & \multicolumn{6}{|c|}{ From out-of-money option } & \multicolumn{6}{|c|}{ From at-the-money option } \\
\hline & Mean & Std & Min & Max & Auto & $\bar{\rho}$ & Mean & Std & Min & $\operatorname{Max}$ & Auto & $\rho$ \\
\hline \multicolumn{13}{|c|}{ One-year default probabilities: } \\
\hline AMR & 9.802 & 8.058 & 0.311 & 33.791 & 0.994 & 0.797 & 3.308 & 3.259 & 0.045 & 13.566 & 0.989 & 0.775 \\
\hline СТВ & 0.112 & 0.367 & 0.000 & 2.730 & 0.940 & 0.770 & 0.019 & 0.080 & 0.000 & 0.795 & 0.888 & 0.699 \\
\hline DDS & 0.033 & 0.042 & 0.000 & 0.198 & 0.957 & 0.651 & 0.002 & 0.006 & 0.000 & 0.048 & 0.884 & 0.188 \\
\hline EK & 0.001 & 0.004 & 0.000 & 0.036 & 0.939 & 0.677 & 0.000 & 0.000 & 0.000 & 0.002 & 0.902 & 0.619 \\
\hline $\mathrm{F}$ & 3.235 & 2.588 & 0.003 & 14.763 & 0.976 & 0.854 & 0.860 & 0.857 & 0.000 & 5.742 & 0.966 & 0.778 \\
\hline GM & 7.731 & 9.970 & 0.017 & 41.668 & 0.993 & 0.972 & 2.574 & 4.270 & 0.000 & 20.658 & 0.989 & 0.925 \\
\hline GT & 0.848 & 0.791 & 0.003 & 4.222 & 0.977 & 0.812 & 0.113 & 0.140 & 0.000 & 0.929 & 0.968 & 0.713 \\
\hline $\mathrm{KBH}$ & 0.071 & 0.112 & 0.000 & 0.588 & 0.980 & 0.019 & 0.010 & 0.022 & 0.000 & 0.131 & 0.966 & -0.037 \\
\hline \multicolumn{13}{|c|}{ Two-year default probabilities: } \\
\hline AMR & 28.704 & 18.392 & 2.478 & 67.296 & 0.996 & 0.943 & 12.353 & 9.776 & 0.752 & 36.588 & 0.994 & 0.910 \\
\hline СТВ & 1.066 & 2.273 & 0.000 & 13.112 & 0.975 & 0.818 & 0.279 & 0.729 & 0.000 & 5.214 & 0.963 & 0.802 \\
\hline DDS & 0.812 & 0.703 & 0.001 & 2.784 & 0.983 & 0.687 & 0.131 & 0.137 & 0.000 & 0.605 & 0.971 & 0.599 \\
\hline EK & 0.135 & 0.267 & 0.000 & 1.618 & 0.985 & 0.801 & 0.011 & 0.029 & 0.000 & 0.200 & 0.971 & 0.697 \\
\hline $\mathrm{F}$ & 15.745 & 8.577 & 0.329 & 38.120 & 0.987 & 0.863 & 6.611 & 4.397 & 0.045 & 19.536 & 0.986 & 0.847 \\
\hline GM & 22.611 & 20.341 & 1.151 & 66.385 & 0.991 & 0.986 & 9.616 & 11.711 & 0.112 & 42.363 & 0.993 & 0.970 \\
\hline GT & 6.058 & 3.477 & 0.447 & 19.845 & 0.983 & 0.879 & 1.587 & 1.156 & 0.058 & 7.282 & 0.978 & 0.821 \\
\hline $\mathrm{KBH}$ & 1.335 & 1.122 & 0.009 & 5.095 & 0.989 & 0.340 & 0.300 & 0.381 & 0.000 & 1.680 & 0.988 & 0.203 \\
\hline \multicolumn{13}{|c|}{ Three-year default probabilities: } \\
\hline AMR & 41.376 & 21.973 & 6.651 & 81.109 & 0.996 & 0.959 & 21.152 & 14.182 & 2.723 & 52.169 & 0.994 & 0.933 \\
\hline СТВ & 2.702 & 4.681 & 0.000 & 23.995 & 0.981 & 0.823 & 0.882 & 1.813 & 0.000 & 10.697 & 0.977 & 0.828 \\
\hline DDS & 2.702 & 1.916 & 0.031 & 7.508 & 0.985 & 0.655 & 0.677 & 0.577 & 0.001 & 2.352 & 0.980 & 0.632 \\
\hline EK & 0.652 & 0.992 & 0.000 & 5.285 & 0.988 & 0.825 & 0.087 & 0.183 & 0.000 & 1.070 & 0.982 & 0.732 \\
\hline $\mathrm{F}$ & 26.971 & 12.132 & 1.438 & 55.102 & 0.986 & 0.861 & 13.424 & 7.491 & 0.348 & 32.729 & 0.986 & 0.836 \\
\hline GM & 28.763 & 18.319 & 3.612 & 69.028 & 0.969 & 0.860 & 16.605 & 16.903 & 0.658 & 59.480 & 0.994 & 0.943 \\
\hline GT & 12.838 & 6.038 & 1.975 & 32.946 & 0.981 & 0.861 & 4.457 & 2.563 & 0.387 & 15.092 & 0.980 & 0.802 \\
\hline KBH & 4.081 & 2.614 & 0.136 & 12.174 & 0.985 & 0.549 & 1.220 & 1.121 & 0.008 & 4.571 & 0.989 & 0.447 \\
\hline
\end{tabular}



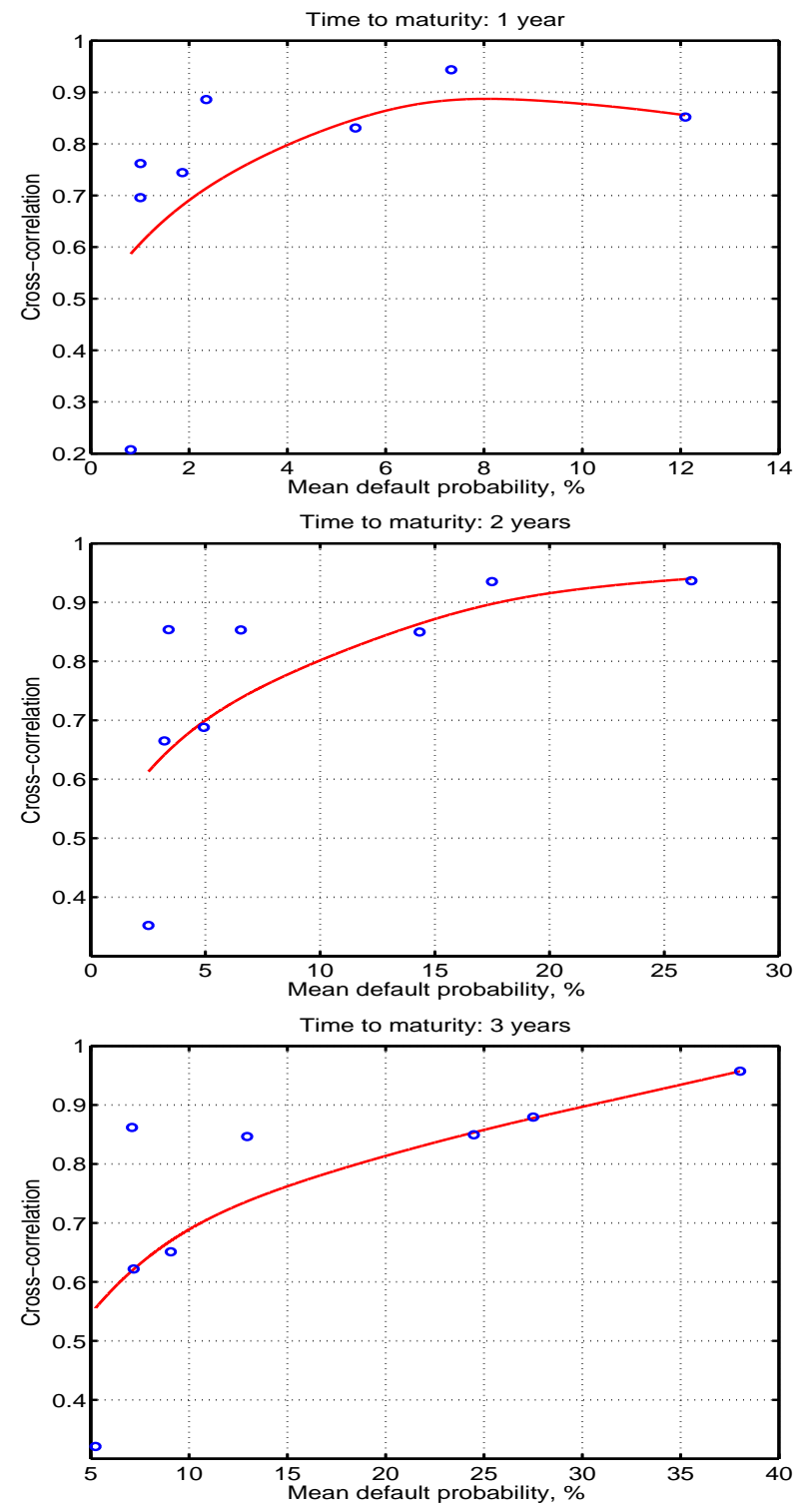

Fig. 1. Cross correlations as function of mean default probabilities.

The graphs show the relation between the mean default probability level (computed from the CDS market) and the cross-correlation estimates between the default probabilities computed from the two markets. The dots are data points. The lines are local-linear smoothing fits. Each panel represents one maturity. 

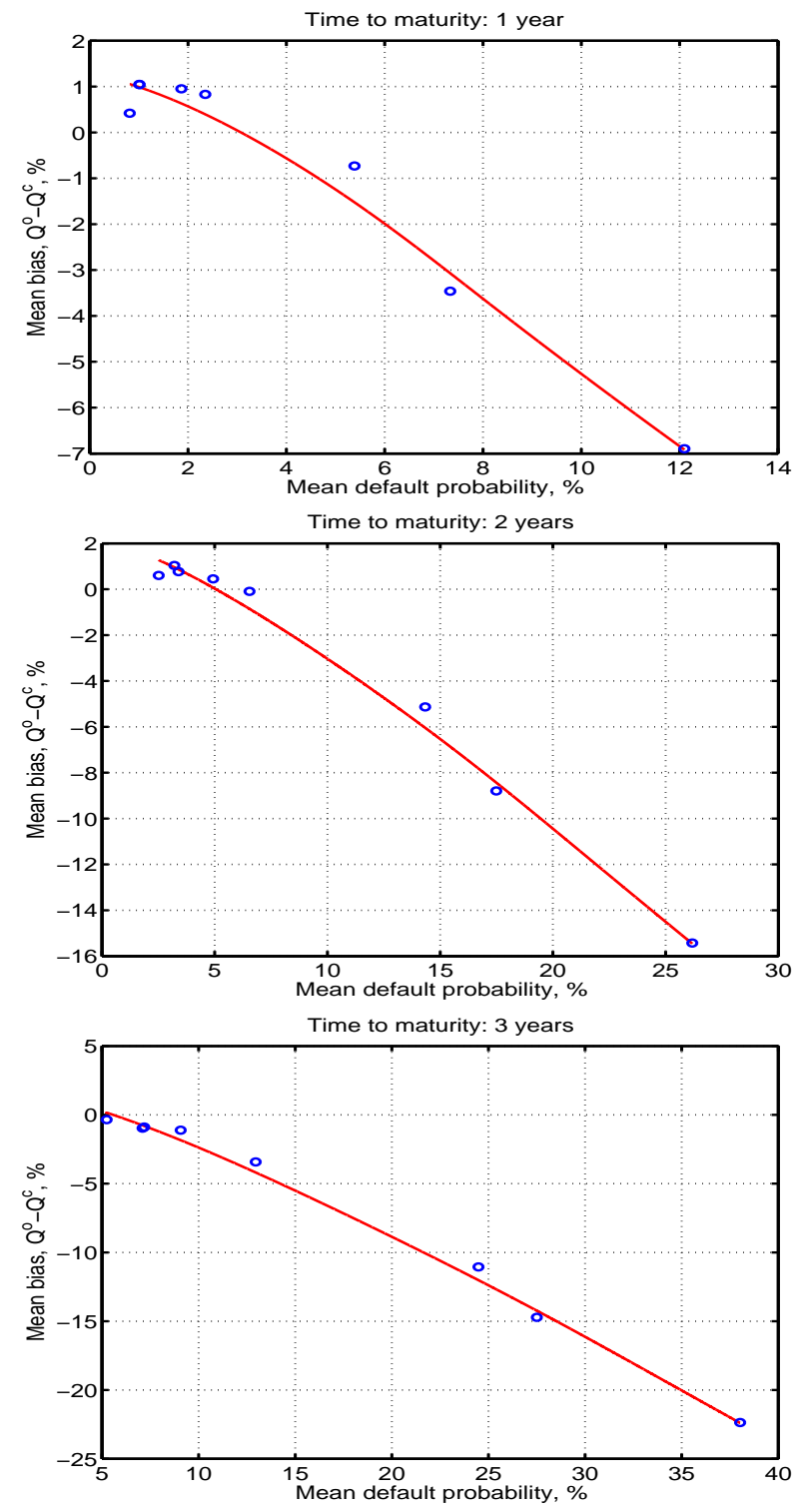

Fig. 2. Mean biases in default probabilities.

The dots in each panel represent the mean difference between the default probabilities estimated from the options market and that from the CDS market. The solid lines are local-linear smoothing fits. Each panel represents one maturity. 

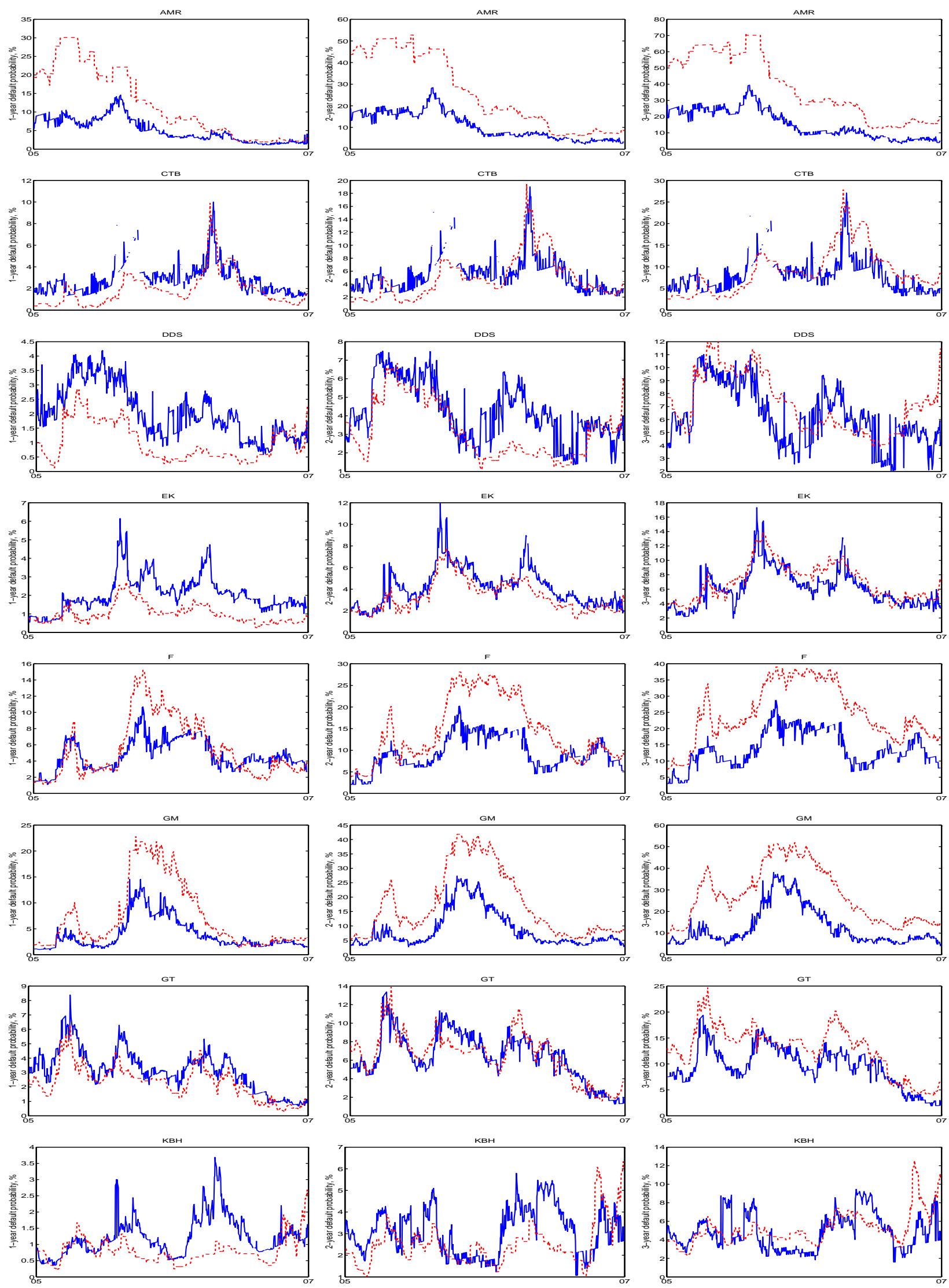

44

Fig. 3. Comparing the time series of one-year default probabilities computed from two markets. The solid line in each panel denotes the time series of the risk-neutral default probabilities estimated from the American put spreads, and the dashed line represents the time series estimated from the CDS spreads. Each panel represents one reference company and one maturity. 

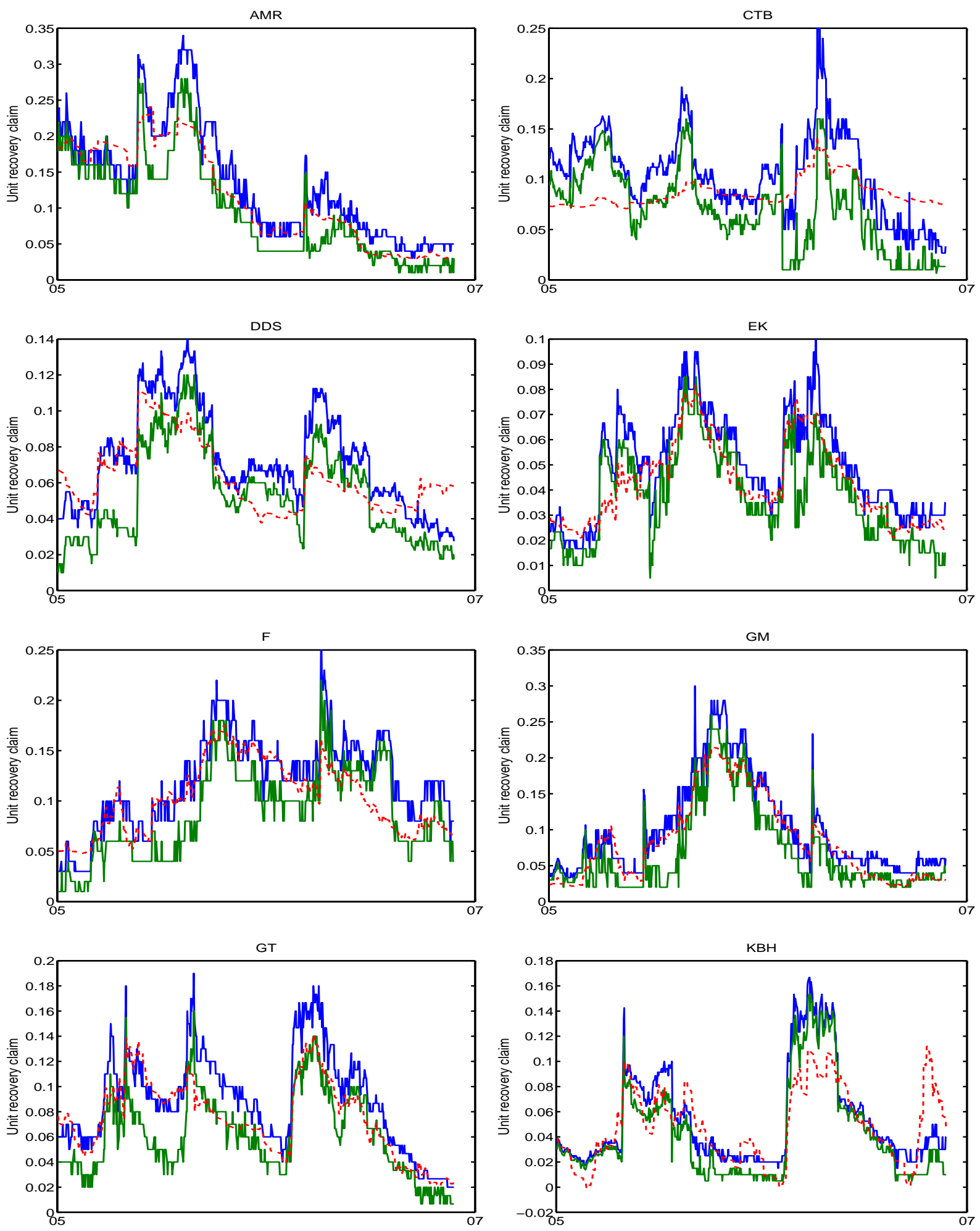

Fig. 4. Tracing the unit recovery values.

The solid lines are the market values of the unit recovery claim synthesized from American put options. The dashed lines are the estimated values from the CDS quotes based on constant interest rate and default arrival rate assumption and linear interpolation on the CDS quotes. 

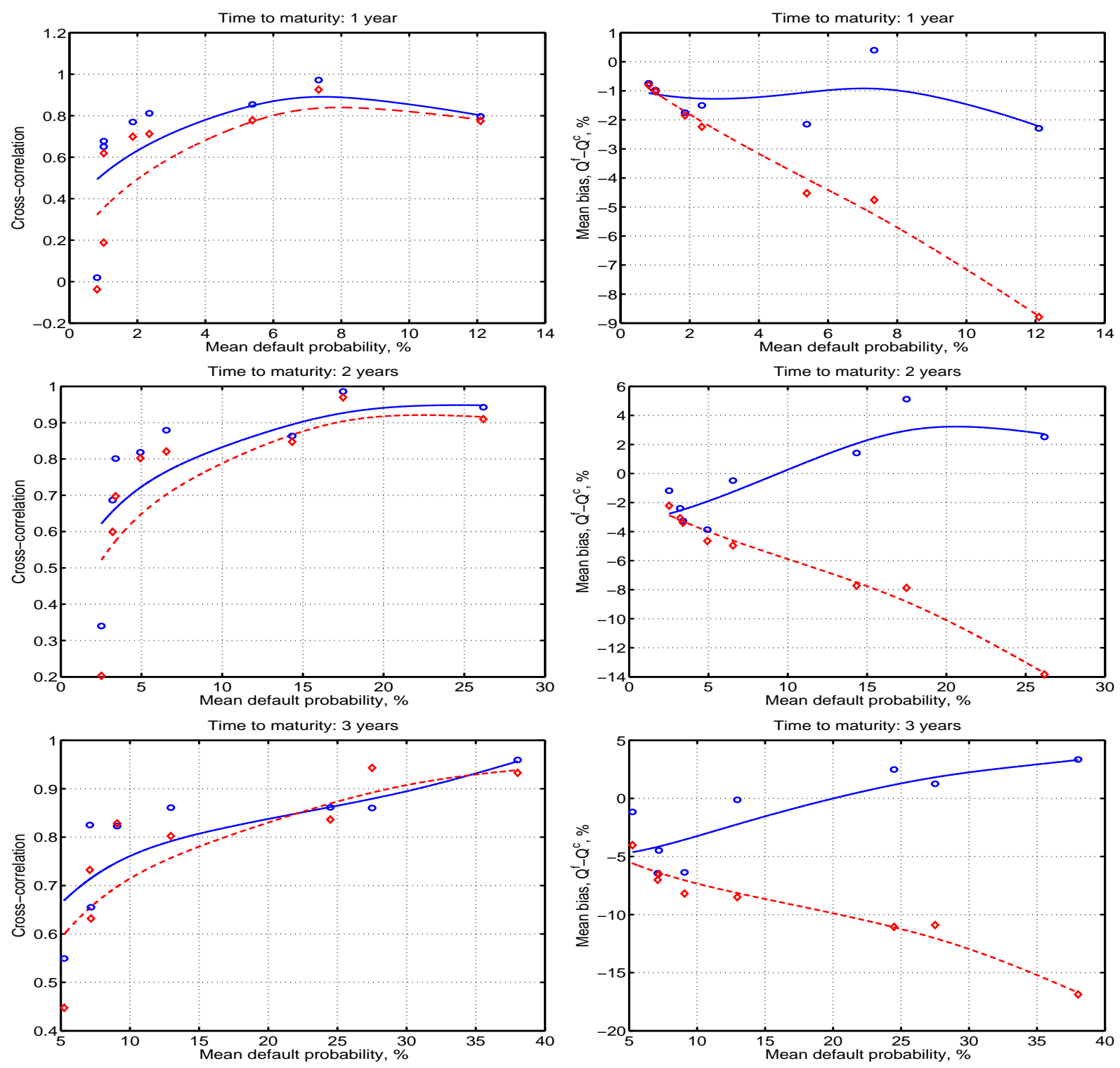

Fig. 5. Cross correlations and mean biases as function of mean default probabilities.

The graphs on the left hand side show the relation between the mean default probability level (computed from the CDS market) and the cross-correlation estimates between the default probabilities computed from the two markets. The graphs on the right hand side plot the mean difference in probability between the structural approach and the CDS market, $\mathbb{Q}^{f}-\mathbb{Q}^{c}$, as a function of the mean default probability for each firm. The dots (data) and solid lines (smoothed fitting) are based on out-of-the-money implied volatilities. The diamonds (data) and dashed lines (smoothed fitting) are based on at-the-money implied volatilities. Each panel represents one maturity. 